\title{
11 Phenotypic Plasticity in the Fossil Record
}

\author{
Adrian M. Lister \\ The Natural History Museum, London
}

\section{CONTENTS}

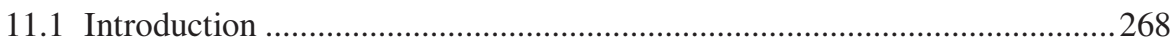

11.2 Identifying Phenotypic Plasticity in the Fossil Record .............................269

11.2.1 Correlation with Paleoenvironmental Variation..............................269

11.2.1.1 Analogy with Living Relatives ..................................... 271

11.2.1.2 The Pattern of Variation ................................................. 273

11.2.1.3 Parallel Change across Species.................................... 275

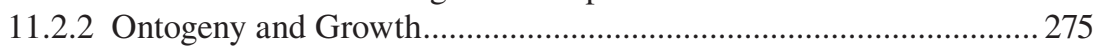

11.2.2.1 Magnitude of Change................................................... 275

11.2.2.2 Relative Growth ............................................................ 276

11.2.2.3 Growth Influenced by Substrate ..................................... 276

11.2.3 Behavioral Traces ......................................................................... 277

11.2.4 Speed and Reversibility of Change.............................................. 277

11.2.5 Variation within a Single Genetic Individual ................................ 278

11.2.5.1 Variation of Growth Rate............................................. 278

11.2.5.2 Bilateral Asymmetry ................................................279

11.2.5.3 Variation within Colonial Organisms ............................2 279

11.2.5.4 Behavioral Variation of a Single Individual ....................280

11.2.6 Direct Genetic Evidence .............................................................. 280

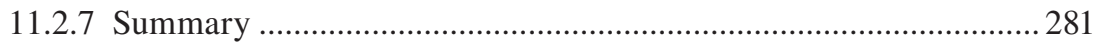

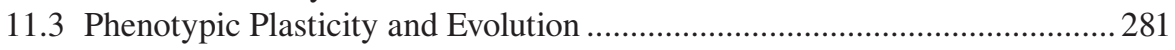

11.3.1 Production and Maintenance of Adaptive Plasticity ....................... 281

11.3.2 Plastic Variation, Selection, and Assimilation ............................... 283

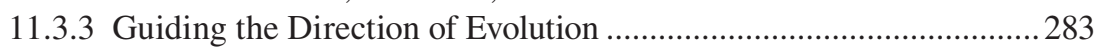

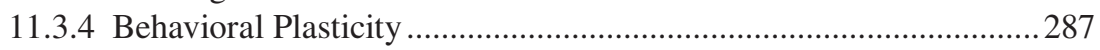

11.3.5 Inhibition of Evolution and Extinction .........................................290

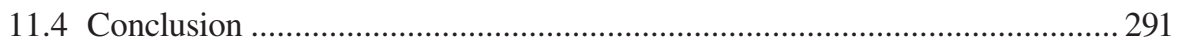

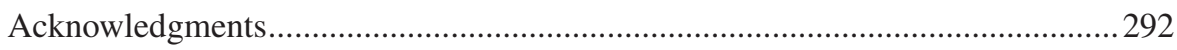

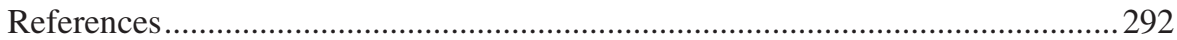




\subsection{INTRODUCTION}

Phenotypic plasticity, the ability of an individual organism to express different phenotypes in response to varying environmental conditions, is ubiquitous across life's diversity. It is also increasingly recognized as fundamental to the survival and adaptive capacity of organisms, as well as forming an integral part of the evolutionary process (West-Eberhard 2003; see also Pfennig 2021 and Sultan 2021 in this volume). We can suppose as a working assumption that what is true today must have also been true for organisms in the past (Chauffe and Nichols 1995). While almost all research on phenotypic plasticity has been based on living organisms, the fossil record has the potential to test models of biological processes with resources not amenable to the biology of the present-day:

- Long time-series to trace phenotypic change and variability on timescales ranging from $10^{0}$ to $10^{9}$ years

- Extinct relatives of living taxa, as models of ancestral phenotype and variation

- Quantification of diversification and extinction in clades through time

Evolutionary hypotheses that could in principle be tested in the fossil record include the origin of adaptive plasticity in heterogeneous environments; the reduction of plasticity in more stable environments; the role of plasticity (including behavioral plasticity) in promoting and guiding evolution and dispersal; and the part played by plasticity in major evolutionary transitions. Addressing such questions, however, makes high demands of the fossil record (Webster 2019). A more-or-less continuous fossil sequence through an adequate period of time would be required to track changes in phenotype and its plasticity, with associated evidence of ancient environments to test for potentially causal or adaptive factors. Ideally, we would also require time-correlated sequences in different areas to account for habitat variation and dispersal. And each time/space unit should be represented by sufficient fossils of the lineage under study to represent variation within the population and allow statistical testing between samples. Addressing these questions in the fossil record is usually not, therefore, a matter of choosing one's preferred taxonomic group and getting to work, but carefully selecting a taxon and geological setting that fulfills, or partly fulfills, the above criteria.

Moreover, testing these ideas presupposes that it is possible to determine how far morphological change was generated by developmental plasticity or genetic differentiation. Often challenging in living species, for fossils it is harder still (Newell, 1947; Dynowski and Nebelsick 2011; Webster 2019). Unlike present-day studies, we cannot undertake field transplants, laboratory manipulation of conditions, breeding experiments, or (except in very rare cases) access the genotype. All we have is morphology, normally restricted to hard parts, and sometimes traces of the organism's activity in life. These challenges, and the solutions that have been proposed to deal with them, will first be surveyed (Section 11.2). We will then explore to what extent fossil data can be brought to bear on the major evolutionary questions where phenotypic plasticity has been implicated (Section 11.3). 


\subsection{IDENTIFYING PHENOTYPIC PLASTICITY IN THE FOSSIL RECORD}

Many paleontological papers, acknowledging that observed variation might be due either to plasticity or to genetic differentiation, explicitly decline to choose between them. Yet a variety of distinguishing criteria have been proposed (e.g., Lister 1992; McKinney and McNamara 1991; Chauffe and Nichols 1995; Schoch 2014; Jackson 2020), and an account of them illustrates the great diversity of fossil examples in which phenotypic plasticity (often referred to as ecophenotypy in the paleontological literature) has been explored, from protists to humans, and from the earliest known fossils up to the historical period (Box 11.1). Note that in many cases several of the factors listed below are taken together to support the identification of phenotypic plasticity.

\section{BOX 11.1 THE GEOLOGICAL TIMESCALE: MYR, MILLIONS OF YEARS AGO}

\begin{tabular}{|c|c|c|c|c|c|}
\hline Eon & Era & \multicolumn{2}{|l|}{ Period } & Epoch & Start Date (Myr) \\
\hline \multirow{16}{*}{ Phanerozoic } & \multirow{7}{*}{ Cenozoic } & \multirow{2}{*}{\multicolumn{2}{|c|}{ Quaternary }} & Holocene & 0.012 \\
\hline & & & & Pleistocene & 2.6 \\
\hline & & & \multirow{5}{*}{ Tertiary } & Pliocene & 5.3 \\
\hline & & Neogene & & Miocene & 23 \\
\hline & & \multirow{3}{*}{ Paleogene } & & Oligocene & 34 \\
\hline & & & & Eocene & 56 \\
\hline & & & & Paleocene & 66 \\
\hline & \multirow{3}{*}{ Mesozoic } & Cretaceous & & & 146 \\
\hline & & Jurassic & & & 200 \\
\hline & & Triassic & & & 251 \\
\hline & \multirow{6}{*}{ Paleozoic } & Permian & & & 299 \\
\hline & & Carboniferous & & & 359 \\
\hline & & Devonian & & & 416 \\
\hline & & Silurian & & & 444 \\
\hline & & Ordovician & & & 488 \\
\hline & & Cambrian & & & 542 \\
\hline \multirow{3}{*}{ Proterozoic } & Neoproterozoic & Ediacaran & & & 635 \\
\hline & Mesoproterozoic & & & & \multirow[b]{2}{*}{2500} \\
\hline & Paleoproterozoic & & & & \\
\hline
\end{tabular}

\subsubsection{Correlation with Paleoenvironmental Variation}

Fossil species are often found across a range of locations or time-intervals with evidence of variation in factors such as temperature, salinity, water depth, or predation pressure (Figure 11.1). 


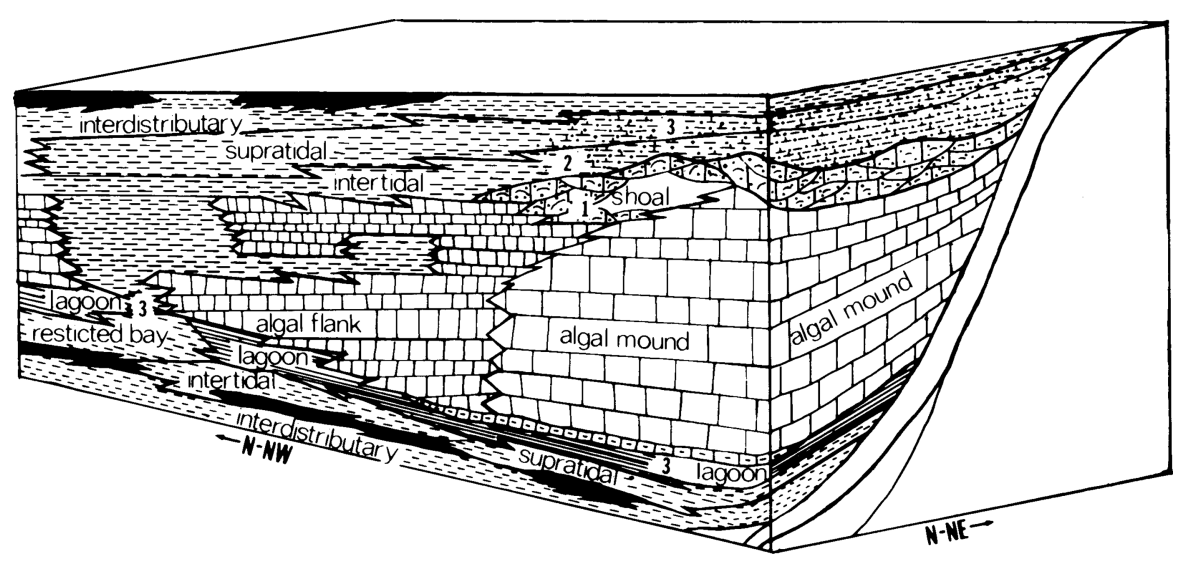

FIGURE 11.1 An example of the reconstruction of paleoenvironmental variation in time and space from rocks deposited in different settings. The block represents an area of approximately $20 \times 10 \mathrm{~km}$ in north-central Illinois during Pennsylvanian (Upper Carboniferous) times; vertical scale greatly exaggerated. Algal mound: a mat of algae in shallow seas that aggrades limestone; algal flank: side of algal mound; interdistributary: area between the channels of a delta; intertidal: shore between high and low tides; shoal: sandbanks off the coast; supratidal: shore above high tide. (Reprinted with permission from Hickey, D.R., Journal of Paleontology, 61, 290-311, 1987.)

These paleoenvironmental factors can be assessed via a variety of proxies, including stable isotopes, the composition of the faunal community, and the nature of the enclosing sediment that reflects aspects such as water flow rate and the nature of the ancient substratum. If across samples with constant environment, the phenotype of the target species remained the same, but with observed environmental differences it varied, phenotypic plasticity is suspected, and in many cases a likely adaptive basis for the correlation can be suggested.

For example, Witts et al. (2020) examined shell shape in Late Cretaceous ammonites (a group of extinct molluscs with coiled shells, related to squid). Tracing the species Hoploscaphites nicolletii across its entire spatial and temporal range, the authors found no directional trend but variations in shell shape correlated with those of paleoenvironmental proxies. Thus, the shells were more compressed in areas of faster water flow where this shape is believed to improve hydrodynamic efficiency, and the authors interpret this as adaptive phenotypic plasticity. In a species of Triassic crinoid (sea lilies, Phylum Echinodermata), Dynowski and Nebelsick (2011) found that deeper-water populations had longer feeding arms than shallow-water ones, and suggested a link to lesser predation pressure and slower water (and nutrient) flow in deeper-water environments. The authors pointed out, interestingly, that "echinoderms can modify their internal skeleton throughout their entire life. The modular construction of the skeleton, consisting of distinct plates on which there is ongoing addition and resorption of material, leads to an extensive ability of the echinoderms to reflect the ambient habitats by ecophenotypic [i.e., plastic] adaptations."

Transitions in the time dimension hold particular interest. In a celebrated example, many lineages of marine invertebrates became dwarfed after the end-Permian Mass 


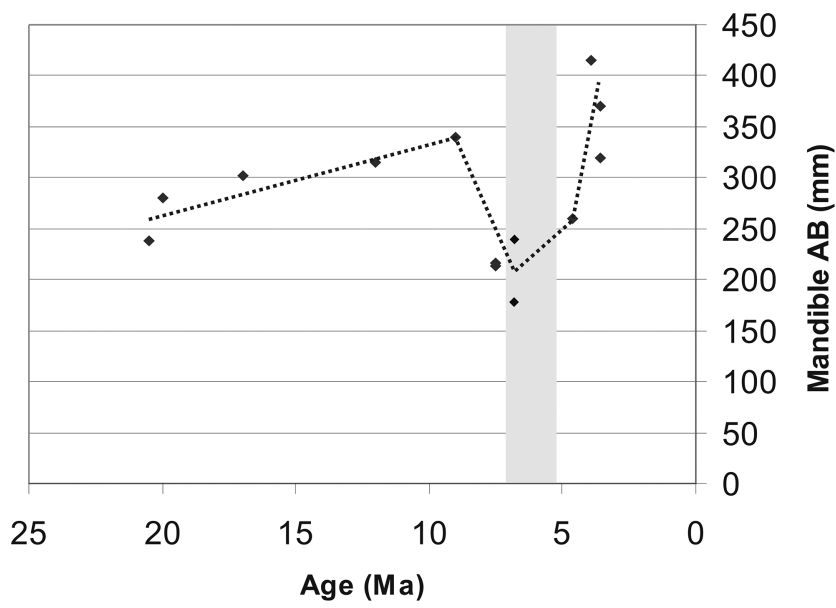

FIGURE 11.2 Variation in mandible length (AB, a measure of body size) in the fossil dugong Metaxytherium. The shaded band marks the Late Miocene Messinian Age (7.24-5.33 Ma). (Reprinted with permission from Bianucci, G. et al., Garyounis Scientific Bulletin, Special Issue 5, 145-157, 2008.)

Extinction, and authors have argued that this was at least in part a result of phenotypic flexibility, particularly in response to known globally low oxygen conditions (Twitchett 2007). Subsequent size increases coincide with increased oxygenation, ocean circulation, and food supply, that would have promoted more vigorous growth (Foster et al. 2020). In mammals too, nutrition is a key determinant of body size attained during growth, and in a Mediterranean lineage of dugong (sea cow) fossils, reduced body size is seen at exactly the time of the 'Messinian salinity crisis' ca. 7-5 million years ago (Myr), when a reduction in the quality and quantity of the sea-grasses, on which dugongs depend, has been inferred (Bianucci et al. 2008; Figure 11.2). The authors propose a direct nutritional cause of the 'dwarfed' phase that lasted some two million years.

An immediate counter to such examples would be that correlation of morphology to environment, especially if adaptive, might be due to natural selection rather than phenotypic plasticity. Additional evidence, beyond mere correlation with paleoenvironment, is desirable to support the interpretation of fossil variation as induced by environmental, rather than genetic, change.

\subsubsection{Analogy with Living Relatives}

Modern experiments and field observations on the plastic response can aid the interpretation of related fossil forms (Hageman and Todd 2014). If the pattern of differences between fossil samples corresponds to known plasticity in closely related extant taxa, plasticity is plausible in the fossil example, especially if there is correlation with the same environmental factors. For example, oysters from relatively crowded situations tend to be more elongate, irregular, and laterally compressed than their non-crowded counterparts; similar observations in fossil oysters are therefore likely to be plastic in origin (Johnson 1981). Individuals of living marine species in brackish-water conditions are often of reduced body size; in a fossil setting, evidence 
for brackish conditions would suggest this cause for observed small individual size. Restricted growth can also be caused by oxygen shortage; this would be suggested by anoxic markers in the rocks enclosing the fossils: fine-grained sediments and the chemical products of sulfur-reducing bacteria (Hallam 1965).

To aid the interpretation of variation in ancient hominins (species closer to humans than to other apes), Anton and Kuzawa (2017) reviewed evidence from contemporary human populations for phenotypic plasticity in traits responsive to variation in climate or nutrition that could be preserved in the fossil record. For example, individuals raised at high altitude have increased lung volume, accommodated by increasing chest dimensions, a pattern potentially visible in fossil remains. In a range of living mammal species, individuals in colder environments tend to have shorter legs, reducing heat loss, and this is at least partly due to phenotypic plasticity; mammals ranging from mice to pigs reared in cold conditions show stunting of appendages and shorter tail lengths (Lister 2004). Analogous variation in fossil species, seen for example in the relatively short limbs of European red deer (Cervus elaphus) in the last glaciation, might therefore be a plastic response (Lister 1997).

The criterion of analogy is clearly less applicable to fossil groups with no living relatives. Even where living relatives are available, caution is warranted, since closely related species do not always respond analogously to the same environmental factors. Transplantation experiments in the living coral Montastrea annularis showed that variation in numerous characters can be completely explained by environmental factors. However, comparing M. annularis with a related Pliocene species Solenastrea fairbanksi, Foster (1979) found that the two species responded to different environmental factors, and highly flexible characters in one species are inflexible in the other (Table 11.1).

Further, the same kinds of differences may reflect evolution in one species and environmentally induced change in another (Raup, 1972), likely by modification of the same developmental pathway. In several lineages of coccolithophores (a major component of phytoplankton), variations of form in time and space, that had been

\section{TABLE 11.1}

\section{Approximate Correlations between Various Morphological Features and Environmental Factors in Two Species of Scleractinian Corals: Pliocene Solenastrea fairbanksi and Living Montastraea annularis}

\section{M. annularis}

Band thickness

Endotheca spacing

Corallite diameter

Theca or exotheca thickness

Septum thickness

Near neighbor distance

Coenosteal void shape

Columella thickness/diameter
(+) light intensity
(+) light intensity
(+) light, nutrients
(-) nutrient supply
(+) water energy
$(-)$ light intensity
(+) water energy
(-) nutrient supply

\section{S. fairbanksi}

(+) nutrient supply

(+) light intensity inflexible

(+) light intensity

(+) light intensity

(+) water energy

(+) water energy

(-) nutrient supply

Source: Data from Foster, A.B., Lethaia 12, 245-264, 1979. 
proposed as phenotypic plasticity within single species, have been shown in the living representatives to be invariant under experimentally varied conditions, and/or to be genetically distinct, thus identifying them as separate species (Geisen et al. 2004).

These considerations apply equally to plants. Barclay et al. (2007) and Royer et al. (2009) summarize phenotypically plastic features in modern leaves with potential use as paleoenvironmental indicators in fossils. These include the dissection of leaves, inversely correlated to temperature; the relative thickness of different cell layers that reflects light intensity; papillae that enhance photosynthesis in deeply shaded habitats; and cuticle thickness as an indicator of aridity. The stomatal density of leaves, in particular, is known to be phenotypically plastic and has been extensively employed in fossil plants to estimate past $\mathrm{CO}_{2}$ levels; the greater the density, the lower the $\mathrm{CO}_{2}$ (Chaloner 1994; Cristophel and Gordon 2004; Figure 11.3). However, the relationship in modern plants is often species-specific, so accurate estimation of paleo- $\mathrm{CO}_{2}$ concentration relies on an ability to assign ancient leaves to modern families, genera, or ideally species, not always possible with fossil material.

\subsubsection{The Pattern of Variation}

In living species, the relationship between an environmental variable and the resultant phenotype of a developmentally plastic character is known as its reaction norm (Sultan 2021). In fossils, a broad reaction norm has been inferred in cases of high level of intraspecific variability, especially in a variable environment (e.g., Hughes 1991 on trilobites; Taylor 2005 on bryozoans; Anton and Kuzawa 2017 on hominins).

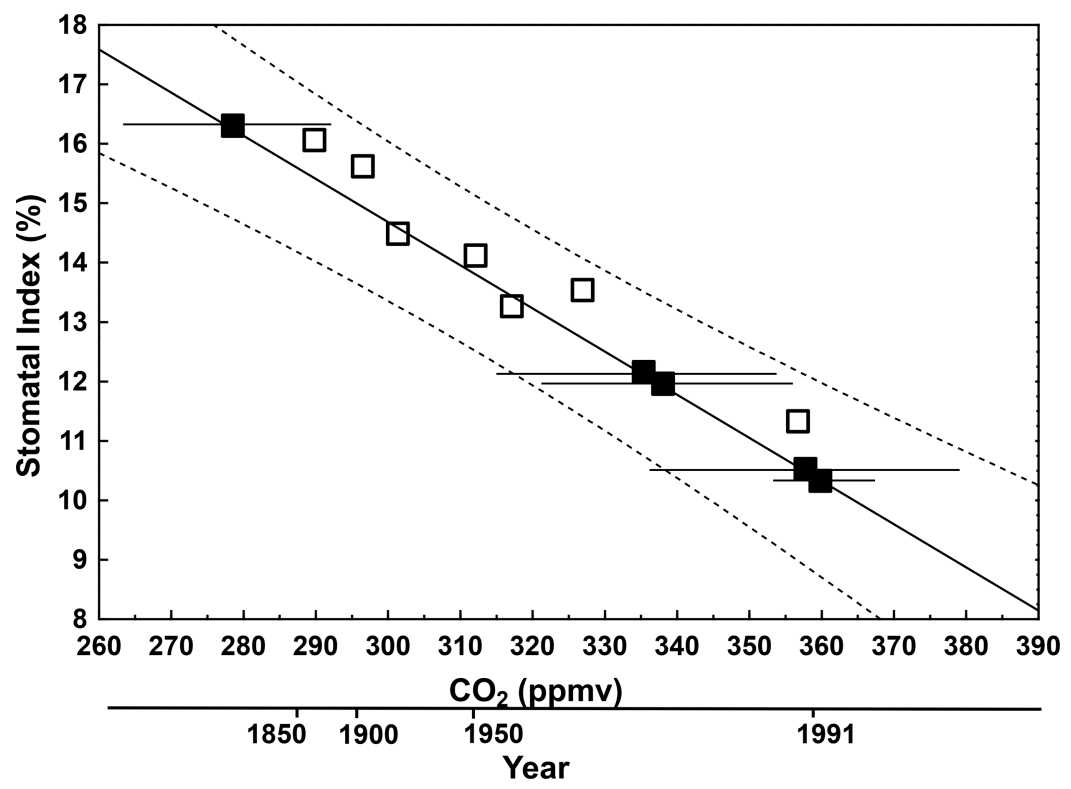

FIGURE 11.3 Stomatal index (density of stomata) in leaves of the oak Quercus petraea in relation to atmospheric $\mathrm{CO}_{2}$. White squares, historical samples since 1850; black squares, fossil samples spanning 10-2 Myr, plotted on modern line to estimate ancient $\mathrm{CO}_{2}$ concentrations. (Adapted from Van der Burgh, J. et al., Science, 260, 1788-1790, 1993.) 
In a stable environment, conversely, these same species should show uniformity as only a small part of the reaction norm would be expressed. Continuous rather than discrete variation is also sometimes taken as a signal of plasticity. In the Cretaceous ammonite Schloenbachia varians, Wilmsen and Mosavinia (2011) found that shell form varied with water depth in a continuously covarying fashion, supporting a phenotypically plastic effect (Figure 11.4).

Caution again attaches to this criterion taken alone, as genetic variation (especially for polygenic characters) can also produce continuous variation, and this can be expressed clinally. Moreover, phenotypic plasticity may be expressed as discontinuous variation producing discrete phenotypes (Pfennig 2021). The possibility that observed variation across conspecific samples reflects genetic differentiation is minimized if samples are both contemporaneous and geographically close. At a given stratigraphic level (i.e., time period), past environmental gradients can often be traced over very short distances in rock exposures, tracking, for example, deeper and shallower parts of a former lake, or nearshore to offshore marine environments (Figure 11.1). In some cases, different paleoenvironments may form a local patchwork. In this case, correlation of intraspecific morphology with environment is likely

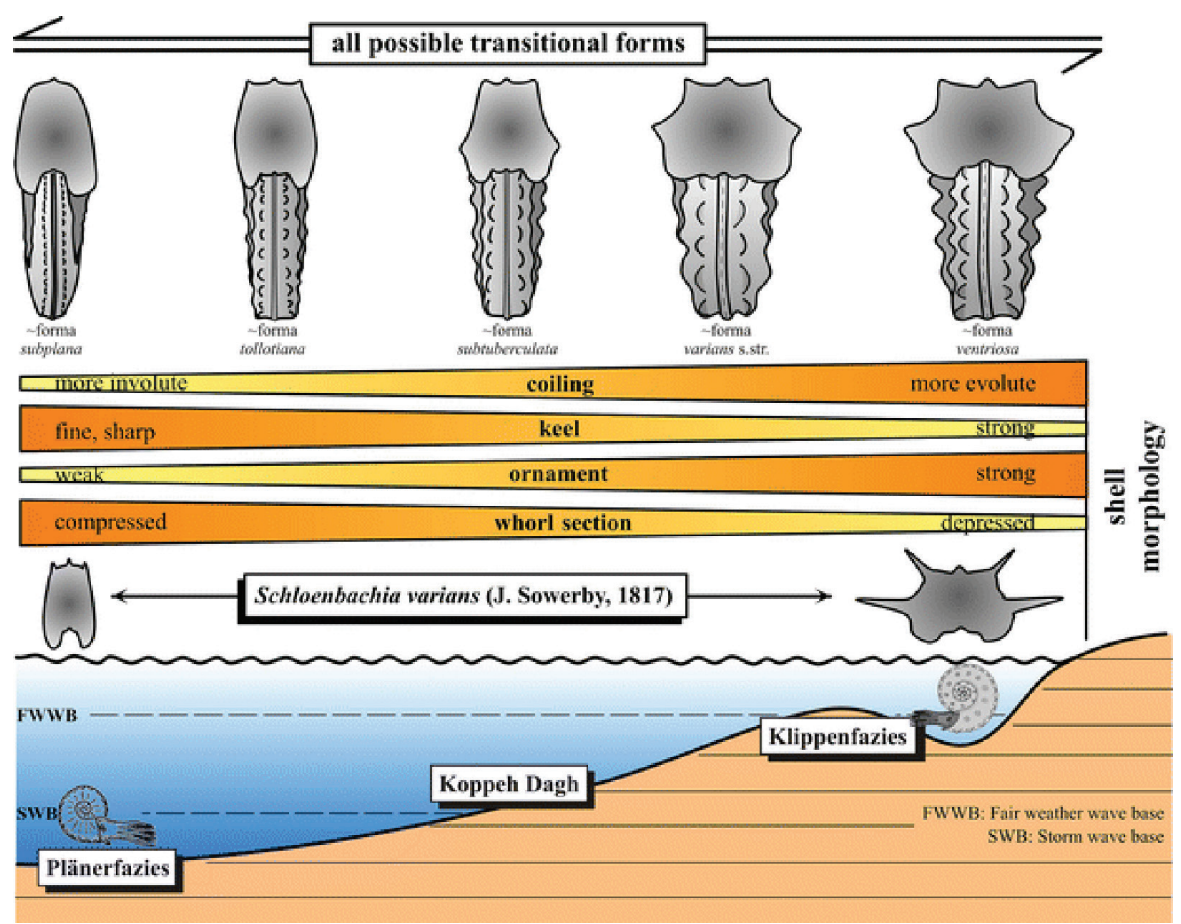

FIGURE 11.4 Schematic representation of clines in the proportion of shell morphs within contemporaneous samples of the Cretaceous ammonite Schloenbachia varians across different paleoenvironments. (Reproduced with permission from Wilmsen, M., and Mosavinia, A., Paläontologische Zeitschrift, 85, 169-184, 2011.) 
due to phenotypic plasticity, since the population as a whole can be inferred to have been interbreeding so local genetic differentiation is unlikely. Distinct morphs that are truly sympatric on the other hand, with no evidence of environmental partitioning, are likely to represent dimorphism or separate species (Geary, 1992).

\subsubsection{Parallel Change across Species}

The simultaneous and similar morphological response of an array of fossil species, particularly when mirroring known common reaction norms in living taxa, has been taken to suggest phenotypic plasticity, especially where the species co-exist (Chauffe and Nichols 1995; Schluter 2016). For example, the increase in size of bivalves in the early Triassic, in combination with evidence for increased oxygen and food availability (see above), led Foster et al. (2020) to suspect phenotypic plasticity because it occurred in parallel across multiple species. Another widely discussed generalization is the 'temperature-size rule': the finding that $80 \%$ of living ectothermic animal species grow to larger size in colder temperatures (Atkinson 1994). Mechanistic explanations have been elusive but life-history modeling suggests that most ectotherms mature at a larger adult size at lower temperatures because of shifts in relative growth rate at different developmental stages (Walters and Hassall 2006). In the fossil record, Hunt and Roy (2006) showed that body size in marine ostracods (tiny crustaceans enclosed in an ovoid shell) of the genus Poseidonamicus, spanning 40 million years of the Cenozoic, was inversely correlated to proxies for ocean temperature. The trends occurred in parallel across species of the genus so that plasticity within similar reaction norms likely contributed to the trends. In bryozoans (sea-mats, a phylum of colonial animals composed of individual zooids), an inverse correlation between water temperature and zooid size in many living species, determined as a phenotypically plastic response, has been utilized in estimating paleotemperatures from multispecies fossil assemblages that show parallel change (Okamura and Bishop 1988).

The degree of parallelism (or divergence) may vary across characters. Thus Sheldon (1987), studying 15,000 trilobites spanning 3 Myr of the Ordovician in Wales, found that eight lineages increased the number of tail ribs, but that times of increase were uncorrelated across taxa, implying selection, whereas fluctuations in body size correlated across taxa and were considered likely phenotypic flexibility.

\subsubsection{Ontogeny and Growth}

\subsubsection{Magnitude of Change}

Authors have assumed that the more profound, complex, or unique a modification, the less likely it is to have arisen by environmental effects on a single genotype, and the more likely to be the result of genetic change (Lister 1992; Anton and Kuzawa 2017). In the celebrated case of the rapid morphological transitions seen in Cenozoic molluscs from Lake Turkana, Kenya, various authors had invoked 'ecophenotypic' (plastic) change, but Williamson (1982) argued for species-level distinctions since "the magnitude of the changes documented in both bivalves and gastropods was generally far greater than that observed in the ecophenotypic transformations of even the most plastic of modern African freshwater molluscs." On this point, he was proven correct although the replacements turned out to be by invasion rather than intra-lineage 
evolution (Van Bocxlaer et al. 2008). Further examples are given for bryozoans (Budd et al. 1994) and deer (Lister 1995) below. This criterion cannot demonstrate plasticity but may suggest its exclusion. Note, however, that several cases of profound morphological alteration are known to have resulted from developmental plasticity (WestEberhard 2003).

\subsubsection{Relative Growth}

Chauffe and Nichols (1995) suggested that if a single element of a complex structure changes, genetic change is probably involved. Environmental effects on development act more broadly; for example, rickets in humans (due to nutritional deficiency) affects many bones of the skeleton. Along similar lines Dececchi et al. (2018), assessing whether related Ediacaran fossils were separate species or 'ecophenotypic' variants, assumed that plasticity would affect developmentally correlated characters, and that individuals differing in a series of uncorrelated characters do so from genetic differentiation. From an ontogenetic perspective Schoch (2014), considering the growth of early fossil amphibians, suggested that in cases of simple truncation or extension of the ontogenetic trajectory, without changes in the sequence of developmental events, plasticity forms as likely an explanation as evolution. If the structure of the trajectory had altered, however, or events producing substantial morphological changes had been added or omitted, genetic innovation was more likely.

By analogy with living representatives, some body parts are expected to be more canalized than others. In mammals, the size and shape of teeth are fixed prior to their eruption, whereas the bony skeleton continues to grow later into the individual's life. The effect of factors such as nutrition, therefore, is most pronounced in the skeleton, whereas variance in tooth size more closely reflects genetic differences (Caumul and Polly 2005). Marshall and Corrucini (1978) suggested that environmentally determined dwarfing could be identified in this way: the animals should retain relatively large teeth for their small skeletons. Many fossil mammals that became dwarfed on islands show this condition, although selective change cannot be ruled out; small breeds of domestic dog, for example, have relatively large teeth (Lister 1995; Lister and Hall 2014).

\subsubsection{Growth Influenced by Substrate}

Modification of growth is sometimes clearly driven by environmental factors. Schrøder et al. (2018) studied the Paleocene brachiopod Obliquorhynchia flustracea, whose larvae settled between the branches of the coral Dendrophyllia candelabrum. Brachiopods are a phylum of marine invertebrates with a laterally-symmetrical double-valved shell, but in O. flustracea many adult shells exhibit an asymmetry that the authors attribute to phenotypic plasticity rather than genetic determination because: (1) the asymmetry can be seen to develop with ontogeny (see Section 11.2.5); and (2) left-twisted and right-twisted morphologies occur in equal numbers (assumed to depend randomly on the constraints of the space and the side the larva settled on). Taylor and Schindler (2004) described fossil bryozoans symbiotic with hermit-crabs, that constructed a gently curved tube extending for up to $50 \mathrm{~mm}$ outward from the aperture of the gastropod shell that was the crab's home. The varying shape of the tube is concluded to be a plastic response to the shape of the crab's body and the curved path of its movement in and out of the shell. 


\subsubsection{Behavioral Traces}

Behavioral flexibility is a 'special case' of phenotypic plasticity as it can be enabled either by pre-programmed alternative behaviors (in most invertebrates) or by 'cognitive intelligence' (in higher vertebrates especially) although the distinction is not absolute and some form of 'learning' is almost universal (Wright et al. 2010; Plotnick 2012; see also Chenard and Duckworth 2021 in this volume). In either case, however, flexible behavior to a given end (e.g., two methods of feeding) falls under the definition of phenotypic flexibility if it is performed by a single genetic individual. Across individuals or populations, the same issues that affect morphological characters also apply to behavior: is observed variation due to genetic differentiation or phenotypic plasticity? Here the difference between 'programmed' and cognitive flexibility (e.g., switching food plant choice in an insect versus in an elephant) becomes significant. In the case of the insect, it would be difficult in the fossil record to know if we are looking at two fixed behaviors in different individuals, or two parts of a common behavioral reaction norm. In the case of a fossil elephant, we may assume individual choice because of the known cognitive flexibility of the family; even if the individuals differed genetically in cognitive ability it would likely not specify particular food species. We are here relying on analogies with living representatives to guide our judgment, as for morphological characters.

Behavioral data comes from traces such as tooth wear or preserved stable isotopes as indicators of feeding preference; skeletal modifications due to use or disuse of body parts; traces of locomotion left on the substrate (if they can be reliably related to the animal that left them); or 'extended phenotype' like burrows and nests (ditto). Examples of behavioral flexibility in fossil populations are numerous and varied (Boucot and Poinar, 2010; Lister, 2014). For instance, feeding switches in sticklebacks, from mid-water to the lake bottom, were identified from tooth-wear and interpreted as likely flexible behavior on the basis of analogous variation in modern populations (Purnell et al. 2007). An unusual example of cognitive flexibility in a mammal was described by Figueirido et al. (2017) who observed dental caries in the population of Pleistocene short-faced bears (Arctodus simus) from Rancho La Brea (California), but not in populations from the north-western USA. They deduced a more omnivorous diet (including sugar-rich fruits) in the La Brea sample, based on the observation that in living bears caries are seen in herbivorous and omnivorous species but not in the largely carnivorous polar bear.

Behavior can exert a direct influence on morphology, a form of "phenotypic accommodation' (West-Eberhard 2003, pp. 51-54). Many studies report alterations in skeletal morphology or bone density as a result of exercise-for example, leftright asymmetry in humerus dimensions in modern tennis players, and Trinkaus et al. (1994) reported greater robusticity in the right humeri of Neanderthals, attributed to strenuous, right-dominant activity.

\subsubsection{Speed and Reversibility of Change}

Since developmental plasticity can modify phenotype within a generation and can revert to the original form with equal speed if the environment reverses, very rapid and/or reversible change has been seen as a signal of plasticity, whereas genetic change is expected to take longer. However, the imperfect resolution of the fossil 
record, especially in the light of known rapid evolutionary changes, militates against this simple 'rule of thumb.' Even the shallowest unit of rock from which we collect fossils is likely to represent a certain interval of time-hundreds, thousands, or even tens of thousands of years, and may also have incorporated dead animals washed in from a catchment including several habitat types (Huntley et al. 2018). Resolving the difference between a process that takes one or a few years (plastic response) from one that might take thousands of years or more (evolutionary response) is therefore difficult (Schoch 2014). The rock record also frequently incorporates gaps in deposition, sometimes invisible in the field, that can make a gradual process appear sudden.

In some situations, the fossil record can be resolved on an annual basis. These are layered sediments deposited at the bottom of lakes or on the seafloor, each layer being a visible record of one year's sedimentation (Schimmelmann et al. 2016), so year-by-year analysis of morphological variation is theoretically possible (Simola 2013). In a study of stickleback fish (Gasterosteus) fossils through an annually resolved sequence from the Miocene of Nevada, Bell et al. (2006) and Purnell et al. (2007) demonstrated an increase in body armor through roughly 150 years, fast but not instantaneous, and the authors concluded that selection was at work. Moreover, studies of modern sticklebacks demonstrate that a transformation of this rapidity is plausible; a newly colonizing lake population showed significant phenotypic change within only 20 years (Aguirre and Bell, 2012), and a notable increase or reduction in body armor can be achieved through mutation of a single control gene (Chan et al., 2010). Hence rapidity of change alone does not uniquely identify phenotypic plasticity in the fossil record; other lines of evidence must be invoked.

Over longer time-periods, fossil morphology constantly fluctuating around a mean has been interpreted as environmentally-induced plasticity. For example, in the Middle Devonian bivalve (clam) Actinopteria boydi, Nagel-Myers et al. (2018) found reversible changes of morphology with no overall trend though 3-4 Myr, and therefore interpreted the fluctuations as plastic in origin. Even here, genetic effects cannot be ruled outreversals in allelic frequencies of a gene under selection could occur in a fluctuating environment. Selection is very likely in cases of long-term directional change (Anton and Kuzawa 2017). Some of the best examples come from microfossils preserved in deep-sea cores, where large samples may be available from finely spaced horizons. In the Eocene planktonic foraminifer Turborotalia cerroazulensis (Protista), gradual transformation of shell shape was observed across 51 horizons spanning some $10 \mathrm{Myr}$ and was interpreted as an evolutionary rather than plastic transformation (Pearson and Ezard 2014).

\subsubsection{Variation within a Single Genetic Individual}

One way of excluding genetic differentiation is to examine variation within a single genetic individual. Any observed morphological or behavioral change is likely to have been a plastic response to the environment.

\subsubsection{Variation of Growth Rate}

Where stages in the ontogeny of an individual are visible in the adult, growth trajectories can be plotted. This can be achieved by following growth rings, or more generally mapping the direction of growth, in shells, bones, or the branches of organisms 
such as corals or plants. Studying the Cretaceous bivalve Actinoceramus sulcatus, for example, Crampton and Gale (2005) found that shell shape through ontogeny did not just change according to a gradual allometric trajectory, but that intermittent switching of growth pattern had occurred, assumed to be driven by external influences during growth. Wang et al. (2004) found greatly varying growth form in the calcareous skeleton of the Carboniferous coral Commutia exolete, due to redirection that kept the oral surfaces of the polyps upward during growth in a muddy substratum.

The ability of an individual to alter its rate of growth through ontogeny, in response to more or less favorable environmental conditions, is a form of phenotypic plasticity. Sanchez and Schoch (2013) compared bone histology across individuals of the Triassic amphibian Gerrothorax pulcherrimus, finding great variability of growth rate as well as in age at maturity and life-span, the variation appearing higher in fluctuating lake environments than in stable ones.

Growth variation can be periodic, suggesting cyclicity in environmental drivers. In the Carboniferous bryozoan Rhombopora blakei, Hageman et al. (2011) identified nested growth cycles that were annual (e.g., monsoon driven), subannual (e.g., periodic storm events), and biweekly (lunar tidal cycles). Indications of seasonal climate changes can also be seen in growth bands of shells, where summer and winter bands can be identified and their relative widths evaluated. Good (2004) analyzed growth bands in five bivalve species through the Late Jurassic of central North America and identified periods with minimal seasonal variation (no visible growth bands) and others with annual climatic cycles (regular growth bands).

\subsubsection{Bilateral Asymmetry}

Morphological variation between the left and right sides of a nominally bilaterally symmetrical organism (also known as fluctuating asymmetry) is considered as an index of developmental canalization (Tucić et al. 2018). It has the inbuilt control that both sides of the organism share the same genotype and generally developed in the same environment (Webster and Zelditch 2008). Hence fluctuating asymmetry is not an index of phenotypic plasticity per se, but a less canalized developmental program might be more likely to also exhibit environmentally controlled plasticity (Tucić et al. 2018). Polly et al. (2011) used left-right asymmetry in molar shape of vole species as a measure of the environmental (non-genetic) component of variance within species. They found that environmental variance accounted for about $10 \%-30 \%$ of within-species variance, suggesting heritabilities of $0.71-0.89$ for molar tooth shape and implying that inter-population differences were likely largely genetically determined. This approach has been considered a major potential area of research into phenotypic plasticity in the fossil record (Webster 2019).

\subsubsection{Variation within Colonial Organisms}

Organisms such as corals and bryozoans form colonies of, respectively, polyps (housed in corallites) and zooids (in zooecia). These provide traction for identifying environmental effects on development, as all individuals of the colony share the same genotype (Hageman 1995). As stated by Budd et al. (1994), "morphologic differences among corallites built by genetically identical polyps at different positions within a colony can be used as a preliminary first step to estimate the magnitude of overall ecophenotypic plasticity within species and to identify the characters that vary" (Figure 11.5). 

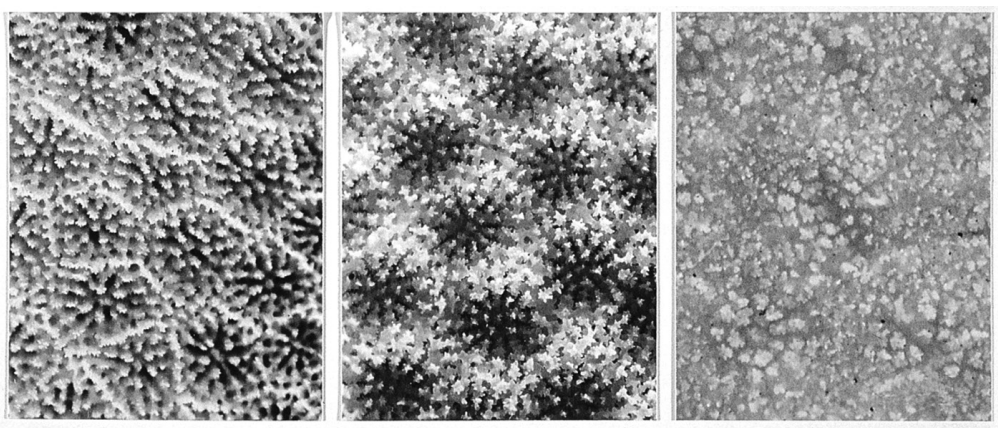

FIGURE 11.5 Variation within a single colony of the coral Porites lutea. Corallites (pouches in the limestone skeleton) are built by genetically identical polyps, revealing developmental plasticity. (Reproduced from Veron, J., Zoological Journal of the Linnean Society, 169, 485-508, 2013, under license CC BY 2.5.)

Thus, Hageman et al. (1999) placed living bryozoan colonies in different experimental conditions and found the form of the colony as a whole, and the size of individual zooids, to be strongly environmentally influenced, while the detailed anatomy of the zooids was less so, and utilized this in interpreting variation in fossil bryozoans.

\subsubsection{Behavioral Variation of a Single Individual}

Trace fossils can sometimes give clues to individual behavioral flexibility (Plotnick 2012). For example, in the Permo-Triassic of Antarctica, four types of trace had been named, but Miller (2003) showed that many individual traces change from one type to another, suggesting that they all represent the same taxon and that its behavior was flexible. Moreover, by analogy with living species, the forms of the traces suggested switching between feeding modes (suspension versus deposit feeding). In Miocene shrimp burrows studied by Miller and Curran (2001), the thickness and definition of burrow walls changed markedly within a single burrow, depending on variation in substrate, and the authors interpreted this as "behavioral plasticity intrinsic to the tracemaking organism."

\subsubsection{Direct Genetic Evidence}

The extraction and sequencing of DNA from fossil material has provided insights into population history and the evolution of functional genes, and more recently of epigenetic and regulatory factors (Linderholm 2015). This field holds a barely tapped potential for exploring evolutionary patterns in the fossil record, including those involving phenotypic plasticity, as both phenotype and genotype are potentially available for the same individuals. Its limits are molecular preservation in only a fraction of fossil material, determined by climatic and sedimentary context, and a shallow time-depth usually to $10^{4}-10^{5}$ years, exceptionally to $10^{6}$ years (Van der Valk et al. 2021). In European red deer (Cervus elaphus), size variation across the climatic cycles of the last glaciation (ca. 50-10 kyr [thousands of years ago]) was suggested to be driven by phenotypic plasticity and no correlation with genetic variation in 
mitochondrial DNA was found (Meiri et al. 2018). A few remains from SE Europe, however, morphologically indistinguishable from red deer but of exceptional size exceeding the bounds of the other samples, were genetically highly divergent, mapping to the related, large Asian species C. canadensis.

\subsubsection{SUMMARY}

Traditional methods of identifying plastic responses in the fossil record warrant caution: the speed and reversibility of plastic change can be mimicked by rapid genetic change, as can correlation of morphology with paleoenvironment. Analogies with living relatives are helpful but may be misleading if related species show different plastic responses. In combination, these factors may be suggestive of plasticity, for example in a case of rapid, parallel response across related species in concert with relevant environmental change, or spatial variation correlating with microenvironments in a single population. More promising for future research is the analysis of variation within single genetic individuals - tracking ontogenetic fluctuations, left-right asymmetry, or variation across a colony (Box 11.2). In the longer term, ancient DNA promises direct insights into the genetic architecture underlying the development of observed phenotypes.

\subsection{PHENOTYPIC PLASTICITY AND EVOLUTION}

Some key hypotheses for the significance of phenotypic plasticity in providing adaptation, and for impacting the process of evolution, are outlined below along with relevant fossil evidence. Insofar as these hypotheses can be tested in the fossil record, we need first to outline the predicted pattern in time and space that would corroborate each one. Figures 11.6-11.8 and 11.10-11.12 present schematic patterns of variation through time under different models. Black lines indicate some fluctuating environmental parameter(s). A, B, and C are expressed phenotypes of a species; if part of a common reaction norm they are marked $\tilde{\mathrm{A}}, \tilde{\mathrm{B}}$, and $\tilde{\mathrm{C}}$. Morphological characters are enclosed in squares, behavioral ones in circles. Pentagons indicate novel morphology or a new species. The various processes are not mutually exclusive (for other summaries of potential mechanisms, see Pigliucci 2001; West-Eberhard 2003; Uller et al. 2019; Pfennig 2021).

\subsubsection{Production and Maintenance of Adaptive Plasticity}

Environmental variability in time and/or space is considered a key promoter and maintainer of phenotypic plasticity (Snell-Rood and Ehlman 2021 in this volume). The idea of selection by and for varying conditions in the fossil record was developed by Potts (1998), who coined the term 'variability selection.' His primary focus was the evolution of the human brain and its capacity for innovation and problem-solving, an adaptation permissive of behavioral flexibility rather than adaptively plastic in itself. However, the principle that environmental variability selects for individuals capable of flourishing in a range of conditions applies also to the origin of phenotypic plasticity (Scheiner et al. 2019; Figure 11.6). 


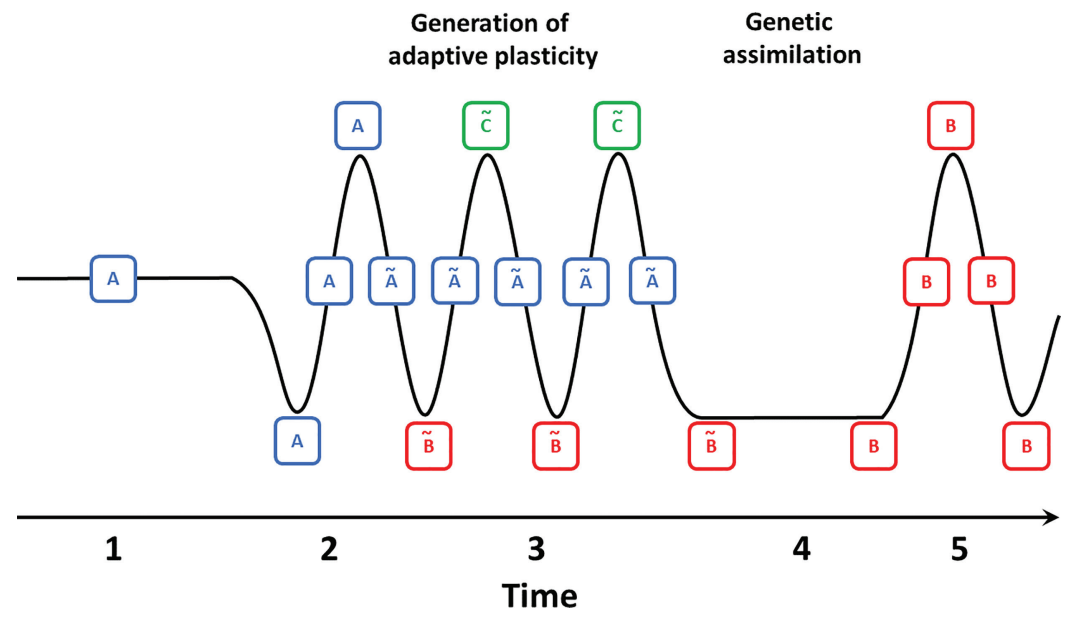

FIGURE 11.6 Generation of phenotypic plasticity followed by genetic assimilation. At time (1) the species begins with a single phenotype in a constant environment; (2) the environment begins to fluctuate but at first the phenotype remains fixed; (3) a range of adaptive phenotypes evolves; they are parts of a reaction norm $\tilde{\mathrm{A}}-\tilde{\mathrm{C}}$; (4) the environment becomes stable in the state where B is favored, so the ' $\mathrm{B}$ ' phenotype becomes canalized; (5) as a result, only ' $\mathrm{B}$ ' is expressed even if the environment begins to fluctuate again (stages 1-3 might begin again). Note that the variation during interval (3) could be expressed spatially as well as temporally.

In discussing the evolution of cognitive faculties in advanced hominins, Potts (1998) suggested the increase in amplitude of Pleistocene climatic cyclicity after $c a$. $750 \mathrm{kyr}$ as the key stimulus. These climatic fluctuations were also invoked by Lister $(1984,2014)$ who suggested that the vegetational shifts to which mainland red deer was subjected, varying between cool grassland, savanna, and temperate woodland, selected for a genotype capable of adaptive developmental modulation. Hence, their living descendants show adaptive plasticity in their feeding adaptations both behaviorally and in their digestive anatomy (Hofmann 1983). By contrast, other species of deer, moose (Alces alces), and roe (Capreolus capreolus), which have more restricted ecological ranges today, tracked woodland habitats in the Pleistocene and are physiologically incapable of consuming large quantities of grass.

Highly variable environmental conditions often characterize small islands. In the dwarf goat Myotragus from the Pleistocene of the Balearic Islands (Spain), Köhler and Moyà-Solà (2009) found limb-bone histology indicating slow and flexible growth rates unlike that of any other mammal, and concluded that developmental and physiological plasticity had been crucial to its survival.

Comparisons across related taxa in the same stratigraphic context indicate different levels of evolved plasticity. Schneider et al. (2010) compared three bivalve genera from a Jurassic sequence in Portugal. In Arcomylitus morrisii, there is variation in shell shape between soft-bottom and sandy environments that may have been adaptive to differing modes of attachment to the substrate. In Eomiodon securiformis and two Isognomon species, by contrast, there was no correlation between shell shape and environmental conditions, implying that an adaptive reaction norm had not evolved in these forms. 


\subsubsection{Plastic Variation, Selection, and Assimilation}

With the return to a more stable environment, phenotypic plasticity may be reduced by selection for an optimal phenotype, potentially leading to canalization through genetic assimilation (Scheiner and Levis 2021 in this volume; Figure 11.6). Modelling suggests that this process could take $10^{4}$ generations (Chevin and Lande 2010) or even $10^{5}$ generations (Scheiner et al. 2019)_implying long-term trends potentially traceable in many fossil sequences.

Several authors have suggested genetic assimilation to account for observed patterns of speciation in the fossil record. In Carboniferous crinoids studied by Holterhoff (1992), the species Delocrinus subhemisphericus displays significant phenotypic plasticity between habitats: smaller size in offshore populations, larger in nearshore ones. The author suggests that offshore, quiet bottom waters inhibited effective filtration, imposing a limit to viable size, while enhanced nutrition in nearshore populations produced larger body sizes. In later horizons, the ancestral D. subhemisphericus persisted in offshore areas but robust new species including D. vulgatus are found in nearshore areas. The author concludes: "Speciation may have involved the stabilization and subsequent diversification of the earlier nearshore phenotype."

In birds, a flexible rate of bone growth, with 'lines of arrested growth' formed during unfavorable intervals and visible in bone cross-sections, was primitive to the fossil stem group but has been lost in all living birds, possibly in parallel between different clades. Starck and Chinsamy (2002) suggest that reduced developmental plasticity may have been selectively favored in connection with the shortened development time of more derived birds, including all those now living.

While these examples assume that the initial plastic variation was adaptive, this is not a prerequisite for its further evolutionary potential. Species accumulate cryptic genetic variation in unexpressed parts of their reaction norm, and a subsequent environmental change beyond previous fluctuating boundaries can induce an array of novel, randomly adaptive phenotypes that provide raw material for selection, a process that has been termed 'plasticity-led evolution' (Levis and Pfennig 2016; see also Levis and Pfennig 2021 in this volume). The observation of a shift in mean phenotype following environmental change in the fossil record does not uniquely identify this process, but Jackson (2020) proposed a test for plasticity-led evolution: increased phenotypic variability in a population encountering a new environment, followed by reduction in variability as the environment and phenotype stabilise (Figure 11.7). In a fossil setting, excellent stratigraphic control would be required to convincingly demonstrate this pattern, as increased variability might result from time-averaging of fossils undergoing rapid phyletic change, or the immigration of a related form and its co-existence with the incumbent (Lister et al. 2005).

\subsubsection{Guiding the Direction of Evolution}

Because of its speed of reaction, phenotypic plasticity will often be the first response of species confronted with an environmental challenge, enabling survival while the slower process of selection takes effect, an effect known as 'buying time' (Fox et al. 2019; see also Diamond and Martin 2021 in this volume; Figure 11.8). Moreover, 


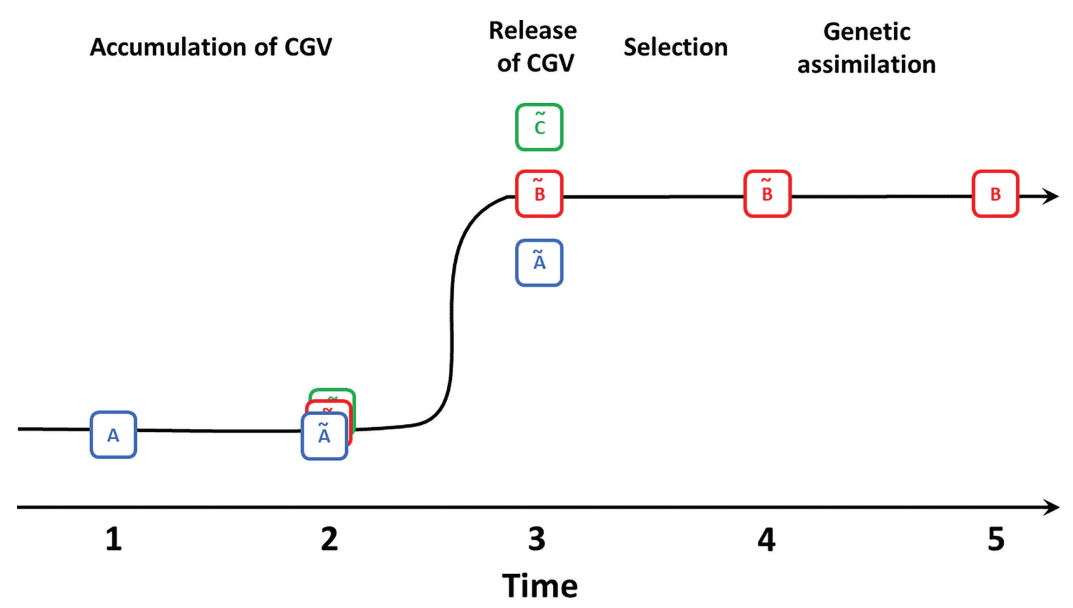

FIGURE 11.7 The 'Plasticity-Led Evolution' model. (1) Single canalized phenotype; (2) cryptic genetic variance (CGV) has accumulated, i.e., (hidden) reaction norms; (3) environment changes, development is altered, CGV is released, revealing an array of unselected phenotypes and reaction norms (e.g. $\tilde{\mathrm{A}}-\tilde{\mathrm{C}}$ ); (4) selection among genotypes; here, a reaction norm with $\tilde{\mathrm{B}}$ expressed is favored; (5) new environment stabilizes, genetic assimilation narrows reaction norm to $\mathrm{B}$. Assimilated forms of $\mathrm{A}, \mathrm{B}$, or $\mathrm{C}$ could seed new species as in Figure 11.10. Compare Jackson (2019, Figure 4).

\section{Morphological plasticity}

\section{Genetic assimilation and/or morphological evolution}

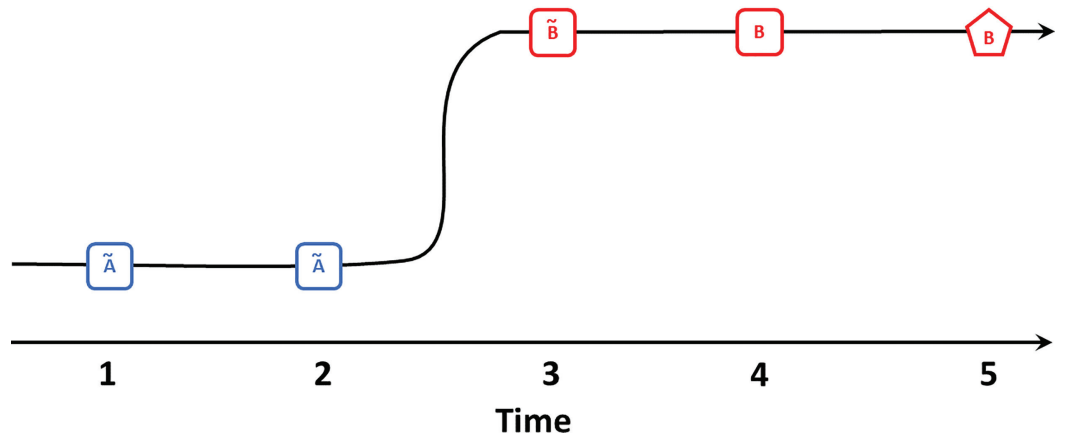

FIGURE 11.8 Guiding evolution with plastic morphological lead: (1)-(2) Ã, starting morphology, part of an adaptive reaction norm; (3) $\tilde{\mathrm{B}}$, another part of the reaction norm is induced by, and allows survival in, new environment ('buying time'); (4)-(5) natural selection further adapts morphology B to fit new environment, possibly with genetic assimilation.

the mode of accommodation may influence the nature of subsequent morphological adaptation (Baldwin 1902). Observing this process in the fossil record is tricky because the transition from plasticity to genetic control as the developmental basis for observed morphological change is difficult to identify in most cases. 
In a study of early multicellular animals known as rangeomorphs, Hoyal Cuthill and Conway Morris (2017) employed a modelling approach to suggest that phenotypic plasticity may have enabled the evolution of large body size in this group. Reaching up to $2 \mathrm{~m}$ in length, rangeomorphs from 570 Myr ago show a size increase of one to two orders of magnitude in comparison with earlier representatives. The authors assumed that growth in the frond-like animal was correlated to nutrient uptake and that this would be proportionately higher in the fine terminal branches because of their high surface area to volume ratio (Figure 11.9). This produced a positive feedback loop such that growth was always greater at the leading edge than the base, so that under optimal nutrient conditions size could increase dramatically. The plastic growth program thus provided a developmental mechanism that led to the appearance of large-bodied species at a time of increased regional nutrient supply.

In the opposite direction, phenotypic plasticity in response to food limitation may have initiated the dwarfing of mammals on islands in the Pleistocene, a process that occurred multiple times across taxa and was clearly adaptive. For example, translocation experiments with living red deer indicate plasticity in adult male body mass of ca. 90-250 kg, but Pleistocene red deer on the island of Jersey in the English Channel dwarfed to ca. $36 \mathrm{~kg}$ (Lister 1995). Since island dwarfs also frequently show specialized locomotory and feeding adaptations to their habitat, Lister (1996) proposed a staged process: initial very rapid size reduction through phenotypic plasticity, genetic assimilation and further reduction in size, and a longer period of selected change to fine-tune adaptation.

The 'flexible stem' hypothesis was proposed by West-Eberhard (2003, Ch. 28) and explored by many authors (Wund et al. 2008; Pfennig et al. 2010; Levis and Pfennig 2021), including some paleontologists (Figure 11.10). According to this model, the reaction norm of a phenotypically flexible species could provide the morphological basis for descendent species, including the repeated origin of similar morphologies-parallel evolution.

(a)

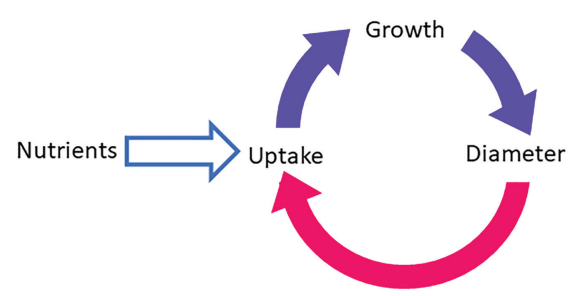

(b)

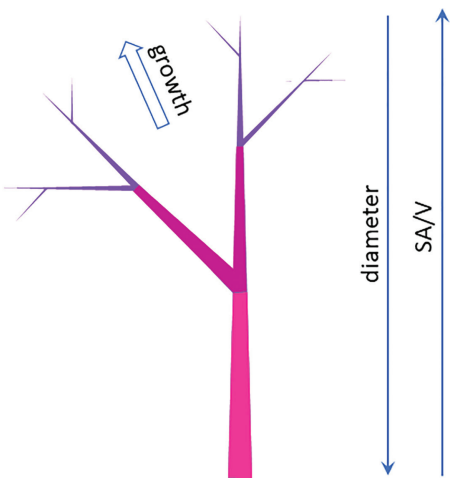

FIGURE 11.9 Computer simulation of rangeomorph growth. (a) Model of feedback between branch diameter, nutrient uptake, and growth. Arrows indicate positive (blue) versus negative (red) effects. (b) Proposed nutrient-dependent growth. Colors indicate the relative proportion of volume by which segments will grow at the next step (blue, high; red, low). SA/V, surface area/volume. (Adapted from Hoyal Cuthill, J.F, and Conway Morris, S., Nature Ecology and Evolution 1, 1201-1204, 2017.) 


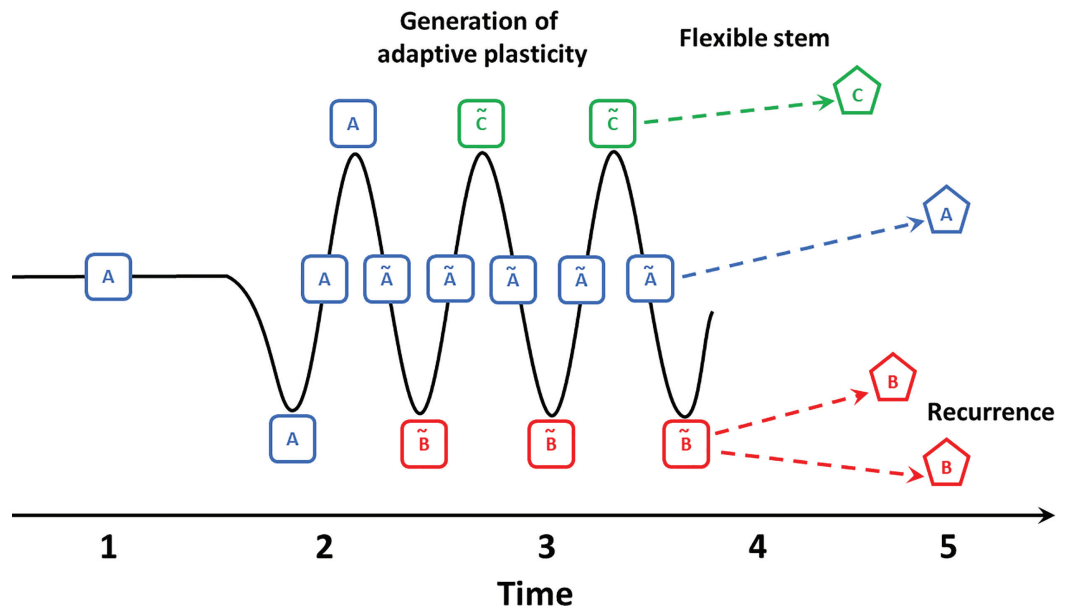

FIGURE 11.10 The 'Flexible stem' scenario: (1)-(3) as in Figure 11.6; (4) populationsbearing phenotypes $\tilde{\mathrm{A}}, \tilde{\mathrm{B}}$, and $\tilde{\mathrm{C}}$ become isolated in, or move to, regions where that morphology is expressed or favored, and (5) may evolve into new taxa A, B, and C, their respective phenotypes possibly becoming fixed by genetic assimilation. Similar daughter taxa (e.g. B) may arise by recurrence (see text).

For example, living amphibians show substantial plasticity in the timing of metamorphosis (the transformation of an aquatic larva into a terrestrial adult), dependent on environmental factors. In Schoch's (2014) study of the Paleozoic to Mesozoic amphibian stem-group, similarly broad reaction norms were identified in many species, and changes in ontogenetic timing produced more strictly aquatic and more terrestrialized forms, that speciated in different environmental contexts. Moreover, phylogenetic analysis indicates that this happened multiple times, an example of parallel evolution likely due to descent from a plastic ancestor, termed 'recurrence' by West-Eberhard (2003).

Phenotypic flexibility should thus favor the exploration of, and survival in, new environments, as well as subsequent adaptation and speciation (West-Eberhard 2003; Sol 2007; Grove 2015; Levis and Pfennig 2021; Figure 11.10). Anton and Kuzawa (2017) outlined criteria for identifying this phenomenon in fossil hominins: the successful disperser should be quite plastic itself, more so than related species, and successive dispersers into similar environments should show parallel phenotypic responses. Grove (2015) developed a modelling approach, predicting that the most favorable situation for successful dispersal was a relatively calm interval following a period of significant environmental perturbation that had selected for enhanced plasticity (see Section 11.3.1). The model was tested on the dispersal of Homo sapiens out of Africa, using paleoclimatic proxies from an East African lake core spanning the last $250 \mathrm{kyr}$ as the environmental signal. The model identified the interval c. 105-97 $\mathrm{ka}$ as the optimum for a significant dispersal event, corresponding very well with the earliest appearance of $H$. sapiens in the Middle East at ca. $100 \mathrm{ka}$.

Has the prevalence of plasticity changed through geological time, and if so, how may this have impacted life's diversification? It has been suggested that the 
'Cambrian explosion' was facilitated by the developmental plasticity of early metazoans (McNamara 1983). In corollary, the decline in origination rate of new metazoan body plans following the early Cambrian might reflect developmental canalization in derived taxa, limiting their ability to evolve forms with radically different body plans. Evidence on this question has come primarily from studies of trilobites (dominant marine arthropods of the Paleozoic) where it has elicited much discussion. Early Cambrian trilobites often display high levels of intraspecific variability (for example, in the number of thoracic segments) that has been interpreted as due to weakly canalized growth, but during the Cambrian there was a trend toward increased regulation of ontogeny (McNamara 1983; Webster 2015). A similar pattern has been suggested for other groups of animals, but whether such 'developmental constraints' would actually inhibit the origination of new body plans is debated (Hughes et al. 1999).

\subsubsection{Behavioral Plasticity}

Behavioral accommodation is likely to be a key factor allowing dispersal into, and survival in, a new habitat. Wright et al. (2010) developed an 'adaptive flexibility hypothesis' for cognitively advanced species whereby a population entering a new habitat would show an increase in behavioral diversity as individuals apply innovative behavioral strategies. Learning by individuals and copying by others will lead to a reduction in behavioral diversity as optimal strategies are achieved. Lister (2013) used stable isotope analysis in African fossil elephants to identify a behavioral switch from consumption of trees and shrubs (browsing) to grasses (grazing) around $8 \mathrm{Myr}$ ago. The switch coincided with the spread of grassland, and the earliest stages were marked by increased variation in feeding strategy within several taxa.

Moreover, behavioral change has long been considered a key initiator of evolutionary innovation (Baldwin 1902, Hardy 1965, Vane-Wright 2014, Chenard and Duckworth 2021). Not only may behavioral accommodation 'buy time' (Figure 11.11), but the manner in which it is achieved can guide the morphological adaptations that result (Hardy 1965; Lister 2014). Moreover, an initial behavioral change may be easier than a morphological one to identify as a plastic response since in cognitively advanced species it can be assumed likely the result of Plotkin's (1988) 'choosing intelligence' rather than genetic programming (see Section 11.2.3).

In order to determine whether behavioral change preceded morphological innovation in the fossil record, we need a time-series including independent evidence of both (Lister 2014). In the fossil elephants studied by Lister (2013), the behavioral switch from browsing to grazing was followed only after several million years by dental adaptations to grazing; a similar pattern is seen in other herbivorous mammals (Lister 2014). In hominins, the origin of bipedal locomotion has been posited to have commenced by facultative upright walking as seen in living chimpanzees (even though their locomotory morphology is adapted to quadrupedal walking), followed by morphological adaptation (Carvalho et al. 2012). In these mammalian examples, cognitive behavioral flexibility is assumed to have played a significant part. Moreover, the morphological changes were directly adaptive to the feeding or locomotory switch initiated in behavior. By contrast, in Miocene stickleback fish (see Section 11.2.4), body armor evolved over 150 years following the shift from 


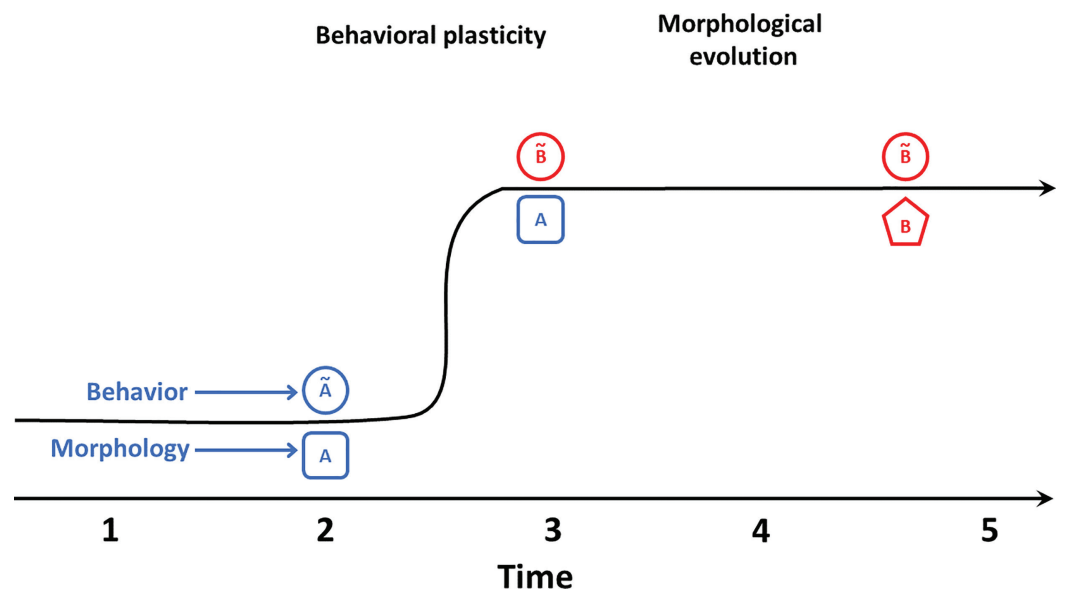

FIGURE 11.11 Guiding evolution with behavioral lead: (1)-(2) coadapted behavior $\tilde{A}$ and morphology A; (3) behavioral flexibility $(\tilde{\mathrm{B}})$ accommodates to new environment, 'buying time,' but morphology (A) stays the same; (4)-(5) natural selection adapts morphology (B) to fit new environment and behavior. Compare Lister (2014, Figure 4).

midwater to benthic feeding (Purnell et al. 2007). This is behavior-led evolution, but (a) the evolutionary response (predator protection) is only indirectly related to the initial behavioral change (location and feeding), and (b) it is unknown whether the behavioral shift was genetically selected or part of a pre-existing behavioral repertoire; only in the latter case would it fall strictly under the definition of phenotypic plasticity.

Behavioral change is also important as a direct inducer of morphological plasticity that is immediately adaptive (Figure 11.12). For example, the adoption of upright posture in hominins has been explored by a feature affected by activity in life: the orientation of bony struts deep within the hindlimb joints, which are known to respond to external loads by orienting their long axes along lines of principal stress. Analysis of these struts using micro-CT scans of fossil tibiae of the 3.5-2.0 Myrold Australopithecus africanus indicates that these hominins primarily adopted an extended, bipedal posture like modern humans and unlike the knuckle-walking of chimpanzees (Barak et al. 2013). The alteration of jaw morphology in living and fossil hominins according to diet (Collard and Wood 2007) is another potential example and is widespread across vertebrates. It is likely that induced morphologies of this type have led to adaptive innovation via genetical assimilation and modification (Wimberger 1994; Figure 11.12).

Plasticity in living species that are relics of ancient ancestors can potentially provide clues to major evolutionary transitions seen in the fossil record. Standen et al. (2014) made an outstanding contribution to our understanding of the origin of tetrapods (land vertebrates) from their fishy ancestors (Figure 11.13). This transition, occurring approximately 400 million years ago, entailed terrestrial locomotion and the evolution of supporting limbs. As stem tetrapods are extinct, a basal member of the extant clade, Polypterus, was used to estimate ancestral 


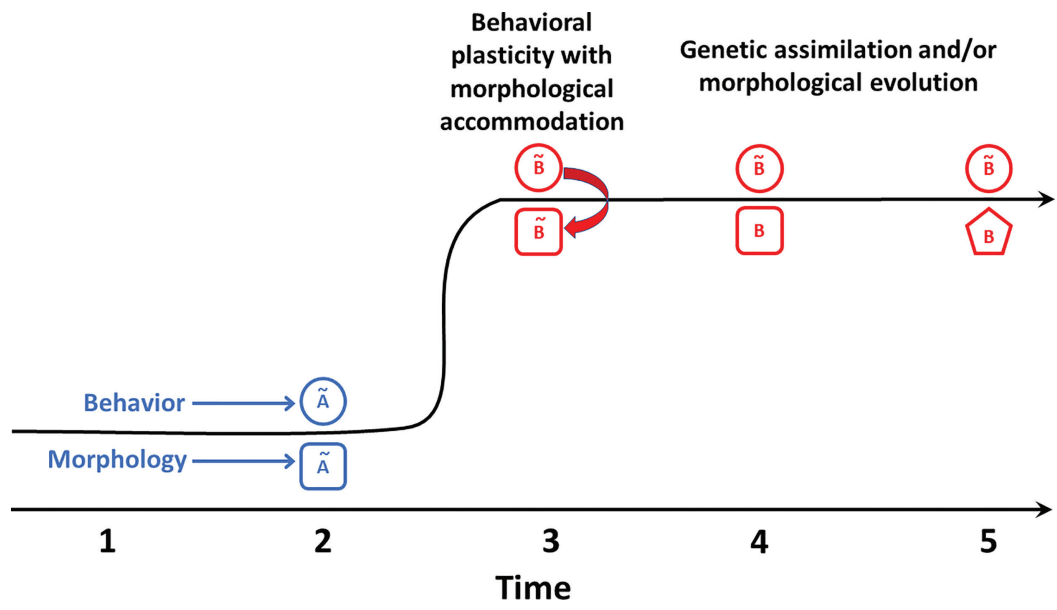

FIGURE 11.12 Behavioral lead with morphological accommodation. (1)-(2) Ã, coadapted starting behavior and morphology, both with reaction norms; (3) behavioral flexibility ( $\tilde{\mathrm{B}})$ accommodates to new environment, modifying morphology ( $\tilde{\mathbf{B}})$ through new usage; (4)-(5) natural selection further adapts and assimilates new morphology.

(a)

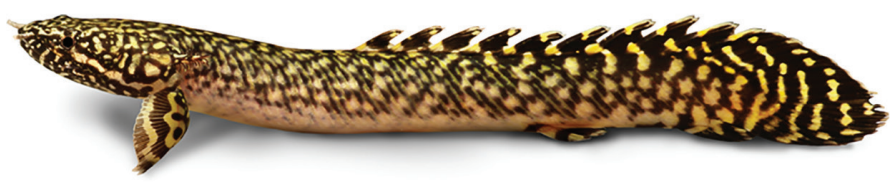

(b)

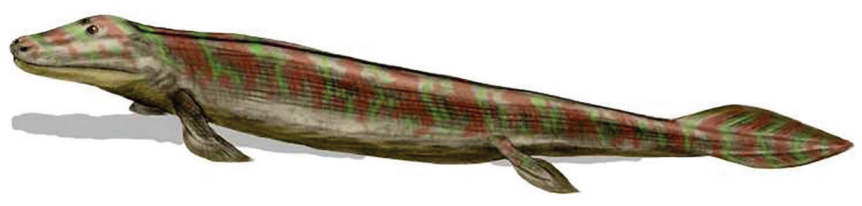

FIGURE 11.13 A modern analogue for the origin of tetrapods. (a) The living bichir Polypterus ( Mirkorosenau/Dreamstime, with permission. (b) Reconstruction of early tetrapod from the Devonian, Tiktaalik. () Nobu Tamura, CC BY_SA.

plasticity; its morphology is in key respects comparable to that of stem tetrapods. This living fish is capable of surviving on land and can walk with its pectoral fins. Standen et al. (2014) found that fish raised on land walked differently from those raised in water, indicating behavioral plasticity. Their fins were planted closer to the body midline and spent less time on the ground, and there were smaller tail oscillations, all reducing energy expenditure. The skeletal anatomy also exhibited phenotypic accommodation in response to terrestrialization, as increased forces in the pectoral girdle induced a modelling response in the bones. 
Crucially, Standen et al. (2014) found that the differences in bone morphology observed between water-raised and terrestrialized Polypterus bore a remarkable resemblance to the evolutionary changes of stem tetrapod pectoral girdles through the water-to-land transition in the Devonian period. With the proviso that Polypterus is only an approximate analogue for long-extinct tetrapod ancestors, and that developmental programs may have altered, it remains plausible that similar behavioral and anatomical changes took place and that phenotypically plastic traits became heritable through genetic assimilation. See Lister (2014) for discussion of earlier ideas on this topic.

\subsubsection{INHIBITION OF Evolution AND Extinction}

Models predict that variability, whether underpinned by genetic variation or plasticity, promotes persistence of a population in the face of environmental change, thereby reducing the risk of extinction (Lande and Shannon 1996; Ducatez et al. 2020). Adaptive plasticity is also theorized, depending on circumstances, to sometimes inhibit evolution by providing immediate and flexible adaptation (Chenard and Duckworth 2021; Diamond and Martin 2021; Pfennig 2021).

In fossil time-series with sufficient resolution, first-order evolutionary trends, or the lack of a trend (stasis), are normally modulated by second-order, short-term fluctuations of form (Voje 2016), and phenotypic plasticity (as well as variation in gene frequencies) are likely mechanisms. Plastic morphological excursions may be adaptive, allowing the species to endure through minor environmental perturbations, and at the same time may dampen selection and thereby promote stasis (West-Eberhard 2003). Thus, Crampton and Gale (2005) documented fluctuation in the expression of radial folds on the shell of the Cretaceous bivalve Actinoceramus sulcatus over some tens of thousands of years, that the authors attribute to plasticity 'maximizing phenotypic adaptability.' Plasticity at the metabolic level in the Triassic amphibian Gerrothorax pulcherrimus, visible in the histology of fossil bones (see Section 11.2.5), allowed the species to survive shifting environments for 35 million years with little change in gross morphology (Sanchez and Schoch 2013).

A major feature of the geological record is the existence of 'reef gaps,' periods characterized by the absence of fossilized coral. This led to the hypothesis that corals have a means of alternating between soft bodies and fossilizing forms. Fine and Tchernov (2007) subjected living coral colonies to acidic $\mathrm{pH}$ values. After a month, their calcareous skeleton dissolved but the polyps survived as free-living individuals. After 12 months, when transferred back to normal $\mathrm{pH}$ conditions, the experimental soft-bodied polyps calcified and reformed colonies. The authors suggest that this phenotypic plasticity could have enabled reef corals to survive past episodes of acidic ocean conditions, accounting for 'reef gaps.'

Extinction resilience via plasticity can also be tested at the community level. In the Plio-Pleistocene extinction event, between ca. 4-1 Myr ago around the coasts of North America, bivalve species that survived were significantly more variable morphologically than victims (Kolbe et al 2011). The authors suggest that greater morphological variation promoted survivorship by enabling adaptation to changing conditions or by 
permitting the occupation of a larger geographic range. The extent to which this variation reflects a plastic response to the environment or genetic diversity is unknown, but this could be in principle tested using the criteria outlined earlier (see Section 11.2).

\subsection{CONCLUSION}

Despite the limitations of fossil data, its time perspective can provide unique insights into the evolutionary process. The role of phenotypic plasticity is particularly challenging to identify in the fossil record as the environmental and genetic influences on morphological variation and change are difficult to separate. However, by bringing the full weight of modern biological understanding to bear on paleontological research, combined with the paleontologist's understanding of the context, limitations, and potential of fossil material, we can unleash great potential for illuminating the complex interaction of genetics, development, and environment in evolution (Box 11.2).

\section{BOX 11.2 SUGGESTIONS FOR FUTURE RESEARCH}

- Collaborative research projects between paleontologists and neontologists (biologists), using insights from living species to inform fossil transitions and vice versa

- Experimental modification of morphology in living species by behavioral change (e.g., of jaw shape by giving different foods, or locomotory apparatus by placing in different topographic settings), to test for replication of evolutionary changes seen in the fossil record

- Surveying for the rare, optimal cases of very finely stratified, richly fossiliferous deposits, with associated paleoenvironmental proxies. Collecting statistical samples of fossils of selected target species level-by-level for tracing patterns of change

- Targeting fossil species with 'inbuilt' indicators of developmental plasticity: where ontogenetic shape change is preserved in adult morphology, where clonal individuals vary, or where fluctuating (left-right) asymmetry can be quantified

- Quantitative testing of the predictions of alternative models involving phenotypic plasticity, such as increased variance in morphology (Jackson 2020) or behavior (Wright 2010) when a species encountered a new paleoenvironment

- Exploitation of behavioral proxies in the fossil record where they can be placed in a time-series with morphological change in the same species, to test for behavioral leads

- Comparison of rates of change in fossil record with populationgenetic models of potential duration of genetic assimilation and other processes

- Targeting of functional and regulatory genes in ancient genomes, in tandem with living relatives where possible, to illuminate the developmental basis of phenotypic changes seen in the species' fossil morphology. 


\section{ACKNOWLEDGMENTS}

I am most grateful to Katie Collins, Matt Grove, Jennifer Hoyal Cuthill, Illiam Jackson, and Jeremy Young for valuable discussion and commenting on parts of the draft manuscript. Feedback from David Pfennig and three anonymous referees substantially improved the final product.

\section{REFERENCES}

Aguirre, W. E. and M. A. Bell. 2012. Twenty years of body shape evolution in a threespine stickleback population adapting to a lake environment. Biological Journal of the Linnean Society 105:817-831.

Anton, S. C. and C. W. Kuzawa. 2017. Early Homo, plasticity and the extended evolutionary synthesis. Interface Focus 7:20170004.

Atkinson, D. 1994. Temperature and organism size-A biological law for ectotherms? Advances in Ecological Research 25:1-58.

Baldwin, J. M. 1902. Development and Evolution. Macmillan, New York.

Barak, M. M., D. E. Lieberman, D. Raichlen, H. Pontzer, A. G. Warrener, and J. J. Hublin. 2013. Trabecular evidence for a human-like gait in Australopithecus africanus. PLoS One 8:e77687.

Barclay, R., J. McElwain, D. Dilcher, and B. Sageman. 2007. The Cuticle Database: Developing an interactive tool for taxonomic and paleoenvironmental study of the fossil cuticle record. Courier Forschungs-Institut Senckenberg 258:39-55.

Bell, M. A., M. P. Travis, and D. M. Blouw. 2006. Inferring natural selection in a fossil threespine stickleback. Paleobiology 32:562-577.

Bianucci, G., G. Carone, D. P. Domning, W. Landini, L. Rook, and S. Sorbi. 2008. PeriMessinian dwarfing in Mediterranean Metaxytherium (Mammalia: Sirenia): Evidence of habitat degradation related to the Messinian Salinity Crisis. Garyounis Scientific Bulletin Special Issue no. 5:145-157.

Boucot A. J., and G. O. Poinar. 2012. Fossil Behavior Compendium. CRC Press, Boca Raton, FL.

Budd, A. F., K. G. Johnson, and D. C. Potts. 1994. Recognizing morphospecies in colonial reef corals: I. Landmark-based methods. Paleobiology 20:484-505.

Carvalho, S., D. Biro, E. Cunha, K. Hockings, W. C. McGrew, B. G. Richmond, and T. Matsuzawa. 2012. Chimpanzee carrying behavior and the origins of human bipedality. Current Biology 22:R180-R181.

Caumul, R. and P. D. Polly. 2005. Phylogenetic and environmental components of morphological variation: Skull, mandible, and molar shape in marmots (Marmota, Rodentia). Evolution 59:2460.

Chaloner, W. G. 1994. Fossil plants as palaeoenvironmental indicators, pp. 13-20. In M. C. Boulter, and H. C. Fisher, eds., Cenozoic Plants and Climates of the Arctic. Springer, Berlin.

Chan, Y. F., M. E. Marks, F. C. Jones, G. Villareal Jr., M. D. Shapiro, S. D. Brady, A. M. Southwick, D. M. Absher, J. Grimwood, J. Schmutz, R. M. Myers, D. Petrov, B. Jonsson, D. Schluter, M. A. Bell, and D. M. Kingsley. 2010. Adaptive evolution of pelvic reduction in sticklebacks by recurrent deletion of a Pitx1 enhancer. Science 327:302-305.

Chauffe, K. M. and P. A. Nichols. 1995. Differentiating evolution from environmentallyinduced modifications in mid-Carboniferous conodonts. Palaeontology 38:875-895.

Chenard, K. and R. A. Duckworth. 2021. The special case of behavioral plasticity? In D. W. Pfennig, ed., Phenotypic Plasticity and Evolution: Causes, Consequences, Controversies. CRC Press, Boca Raton, FL. 
Chevin, L.-M. and R. Lande. 2009. When do adaptive plasticity and genetic evolution prevent extinction of a density-regulated population? Evolution 64:1143-1150.

Christophel, D. and P. Gordon. 2004. Genotypic control and environmental plasticity? Foliar physiognomy and paleoecology. New Phytologist 161:327-329.

Collard, M. and B. Wood. 2007. Hominin homoiology: An assessment of the impact of phenotypic plasticity on phylogenetic analyses of humans and their fossil relatives. Journal of Human Evolution 52:573-584.

Crampton, J. S. and A. S. Gale. 2005. A plastic boomerang: Speciation and intraspecific evolution in the Cretaceous bivalve Actinoceramus. Paleobiology 31:559-577.

Dececchi, T. A., G. M. Narbonne, C. Greentree, and M. Laflamme. 2018. Phylogenetic relationships among the Rangeomorpha: the importance of outgroup selection and implications for their diversification. Canadian Journal of Earth Sciences 55:1223-1239.

Diamond, S. E. and R. A. Martin. 2021. Buying time: Plasticity and population persistence. In D. W. Pfennig, ed., Phenotypic Plasticity and Evolution: Causes, Consequences, Controversies. CRC Press, Boca Raton, FL.

Ducatez, S., D. Sol, F. Sayol, and L. Lefebvre. 2020. Behavioral plasticity is associated with reduced extinction risk in birds. Nature Ecology \& Evolution 4:788-793.

Dynowski, J. F. and J. H. Nebelsick. 2011. Ecophenotypic variations of Encrinus liliiformis (Echinodermata: Crinoidea) from the middle Triassic Muschelkalk of Southwest Germany. Swiss Journal of Palaeontology 130:53-67.

Figueirido, B., A. Perez-Ramos, B. W. Schubert, F. Serrano, A. B. Farrell, F. J. Pastor, A. A. Neves, and A. Romero. 2017. Dental caries in the fossil record: A window to the evolution of dietary plasticity in an extinct bear. Scientific Reports 7:17813.

Fine, M. and D. Tchernov. 2007. Scleractinian coral species survive and recover from decalcification. Science 315:1811.

Foster, A. B. 1979. Environmental variation in a fossil scleractinian coral. Lethaia 12:245-264.

Foster, W. J., J. Gliwa, C. Lembke, A. C. Pugh, R. Hofmann, M. Tietje, S. Varela, L. C. Foster, D. Korn, and M. Aberhan. 2020. Evolutionary and ecophenotypic controls on bivalve body size distributions following the end-Permian mass extinction. Global and Planetary Change 185:103088.

Fox, R. J., J. M. Donelson, C. Schunter, T. Ravasi, and J. D. Gaitan-Espitia. 2019. Beyond buying time: The role of plasticity in phenotypic adaptation to rapid environmental change. Philosophical Transactions of the Royal Society B: Biological Sciences 374:20180174.

Geary, D. H. 1992. An unusual pattern of divergence between two fossil gastropods: Ecophenotypy, dimorphism, or hybridization? Paleobiology 18:93-109.

Geisen, M., J.R. Young, I. Probert, A.G. Sáez, K.-H. Baumann, J. Bollmann, L. Cros, C. DeVargas, L.K. Medlin, and C. Sprengel. 2004. Species level variation in coccolithophores. In H. R. Thierstein et al., eds., Coccolithophores. Springer-Verlag, Berlin.

Good, S. C. 2004. Paleoenvironmental and paleoclimatic significance of freshwater bivalves in the Upper Jurassic Morrison Formation, Western Interior, USA. Sedimentary Geology 167:163-176.

Grove, M. 2015. Palaeoclimates, plasticity, and the early dispersal of Homo sapiens. Quaternary International 369:17-37.

Hageman, S. J. 1995. Observed phenotypic variation in a Paleozoic bryozoan. Paleobiology 21:314-328.

Hageman, S. J., M. M. Bayer, and C. D. Todd. 1999. Partitioning phenotypic variation: Genotypic, environmental and residual components from bryozoan skeletal morphology. Journal of Natural History 33:1713-1735.

Hageman, S. J. and C. D. Todd. 2014. Hierarchical (mm- to km-scale) environmental variation affecting skeletal phenotype of a marine invertebrate (Electra pilosa, Bryozoa): Implications for fossil species concepts. Palaeogeography, Palaeoclimatology, Palaeoecology 396:213-226. 
Hageman, S. J., P. N. Wyse Jackson, A. R. Abernethy, and M. Steinthorsdottir. 2011. Calendar scale, environmental variation preserved in the skeletal phenotype of a fossil bryozoan (Rhombopora blakei n. sp.), from the Mississippian of Ireland. Journal of Paleontology 85:853-870.

Hallam, A. 1965. Environmental causes of stunting in living and fossil marine benthonic invertebrates. Palaeontology 8:132-155.

Hardy, A. 1965. The Living Stream: Evolution and Man. Collins, London.

Hofmann, R. R. 1983. Adaptive changes of gastric and intestinal morphology in response to different fibre content in ruminant diets. Royal Society of New Zealand Bulletin 20:51-58.

Holterhoff, P. F. 1992. Ecophenotypic variation and phylogeny within the Erisocrinacea (Crinoidea): Linkage of morphology, ecology, \& sea - level in the Late Paleozoic. The Paleontological Society Special Publications 6:131-131.

Hoyal Cuthill, J. F. and S. Conway Morris. 2017. Nutrient-dependent growth underpinned the Ediacaran transition to large body size. Nature Ecology and Evolution 1:1201-1204.

Hughes, N. C. 1991. Morphological plasticity and genetic flexibility in a Cambrian trilobite. Geology 19:913.

Hughes, N. C., R. E. Chapman, and J. M. Adrain. 1999. The stability of thoracic segmentation in trilobites: A case study in developmental and ecological constraints. Evolution and Development 1:24-35.

Hunt, G. and K. Roy, 2006. Climate change, body size evolution, and Cope's Rule in deep-sea ostracodes. Proceedings of the National Academy of Sciences 103:1347-1352.

Huntley, J. W., J. D. Schiffbauer, T. D. Avila, and J. S. Broce. 2018. Ecophenotypy, temporal and spatial fidelity, functional morphology, and physiological trade-offs among intertidal bivalves. Paleobiology 44:530-545.

Jackson, I. S. C. 2020. Developmental bias in the fossil record. Evolution \& Development 22:88-102.

Johnson, A. L. A. 1981. Detection of ecophenotypic variation in fossils and its application to a Jurassic scallop. Lethaia 14:277-285.

Köhler, M. and S. Moyà-Solà. 2009. Physiological and life history strategies of a fossil large mammal in a resource-limited environment. Proceedings of the National Academy of Sciences of the United States of America 106:20354-20358.

Lande, R. and S. Shannon. 1996. The role of genetic variation in adaptation and population persistence in a changing environment. Evolution 50:434.

Levis, N. A. and D. W. Pfennig. 2016. Evaluating 'Plasticity-First' evolution in nature: Key criteria and empirical approaches. Trends in Ecology \& Evolution 31:563-574.

Levis, N. A. and D. W. Pfennig. 2021. Innovation and diversification via plasticity-led evolution. In D. W. Pfennig, ed., Phenotypic Plasticity and Evolution: Causes, Consequences, Controversies. CRC Press, Boca Raton, FL.

Linderholm, A. 2015. Ancient DNA: The next generation - chapter and verse. Biological Journal of the Linnean Society 117:150-160.

Lister, A. M. 1984. Evolutionary and ecological origins of British deer. Proceedings of the Royal Society of Edinburgh. Section B. Biological Sciences 82:205-229.

Lister, A. M. 1992. Mammalian fossils and Quaternary biostratigraphy. Quaternary Science Reviews 11:329-344.

Lister, A. M. 1995. Sea-levels and the evolution of island endemics: The dwarf red deer of Jersey. Geological Society, London, Special Publications 96:151-172.

Lister, A. M. 1996. Dwarfing in island elephants and deer: Processes in relation to time of isolation. Symposia of the Zoological Society of London 69:277-292.

Lister, A. M. 1997. The evolutionary response of vertebrates to Quaternary environmental change, pp. 287-302. In B. Huntley, ed., Past and Future Rapid Environmental Changes: The Spatial and Evolutionary Responses of the Terrestrial Biota. Springer, Berlin. 
Lister, A. M. 2004. The impact of Quaternary Ice Ages on mammalian evolution. Philosophical Transactions of the Royal Society B: Biological Science 359:221-241.

Lister, A. M. 2013. The role of behavior in adaptive morphological evolution of African proboscideans. Nature 500:331-334.

Lister, A. M. 2014. Behavioral leads in evolution: Evidence from the fossil record. Biological Journal of the Linnean Society 112:315-331.

Lister, A. M. and C. Hall. 2014. Variation in body and tooth size with island area in small mammals: A study of Scottish and Faroese house mice. Annales Zoologici Fennici 51:95-110.

Lister, A. M., A. V. Sher, H. van Essen, and G. Wei. 2005. The pattern and process of mammoth evolution in Eurasia. Quaternary International 126-128:49-64.

Marshall, L. G. and R. S. Corrucini. 1978. Variability, evolutionary rates, and allometry in dwarfing lineages. Paleobiology 4:101-119.

McKinney, M. L. and K. J. McNamara. 1991. Heterochrony. Springer, New York.

McNamara, K. J. 1983. Progenesis in trilobites. Special Papers in Palaeontology 30:59-68.

Meiri, M., P. Kosintsev, K. Conroy, S. Meiri, I. Barnes, and A. Lister. 2017. Subspecies dynamics in space and time: A study of the red deer complex using ancient and modern DNA and morphology. Journal of Biogeography 45:367-380.

Miller, M. F. 2003. Styles of behavioral complexity recorded by selected trace fossils. Palaeogeography, Palaeoclimatology, Palaeoecology 192:33-43.

Miller, M. F. and H. A. Curran. 2001. Behavioral plasticity of modern and Cenozoic burrowing thalassinidean shrimp. Palaeogeography, Palaeoclimatology, Palaeoecology 166:219-236.

Nagel-Myers, J., C. A. McRoberts, and C. W. LaPoint. 2018. Ecophenotypic variability during times of evolutionary stasis in Middle Devonian Actinopteria (Bivalvia, Pterioidea) from New York. Journal of Paleontology 92:388-397.

Newell, N. D. 1947. Infraspecific categories in invertebrate paleontology. Evolution 1:163.

Okamura, B. and J. D. D. Bishop. 1988. Zooid size in cheilostome bryozoans as an indicator of relative palaeotemperature. Palaeogeography, Palaeoclimatology, Palaeoecology 66:145-152.

Pearson, P. N. and T. H. G. Ezard. 2014. Evolution and speciation in the Eocene planktonic foraminifer Turborotalia. Paleobiology 40:130-143.

Pfennig, D. W. 2021. Key questions about phenotypic plasticity. In D. W. Pfennig, ed., Phenotypic Plasticity and Evolution: Causes, Consequences, Controversies. CRC Press, Boca Raton, FL.

Pfennig, D. W., M. A. Wund, E. C. Snell-Rood, T. Cruickshank, C. D. Schlichting, and A. P. Moczek. 2010. Phenotypic plasticity's impacts on diversification and speciation. Trends in Ecology and Evolution 25:459-467.

Pigliucci, M. 2001. Phenotypic Plasticity: Beyond Nature and Nurture. Johns Hopkins University Press, Baltimore.

Plotkin, H. C. 1988. Learning and evolution. pp. 133-164. In H. C. Plotkin, ed., The Role of Behavior in Evolution. MIT Press, Cambridge, MA.

Plotnick, R. E. 2012. Behavioral biology of trace fossils. Paleobiology 38:459-473.

Polly, P. D., L. Killick, and M. Ruddy. 2011. Using left-right asymmetry to estimate nongenetic variation in vole teeth (Arvicolinae, Muridae, Rodentia). Palaeontologia Electronica 14:1-12.

Potts, R. 1998. Environmental hypotheses of hominin evolution. Yearbook of Physical Anthropology 41:93-136.

Purnell, M. A., M. A. Bell, D. C. Baines, P. J. B. Hart, and M. P. Travis. 2007. Correlated evolution and dietary change in fossil stickleback. Science 317:1887-1887.

Raup, D. M. 1972. Approaches to morphological analysis. pp. 28-44. In T. J. M. Schopf, ed., Models in Paleobiology. Freeman, Cooper, San Francisco, CA. 
Royer, D. L., L. A. Meyerson, K. M. Robertson, and J. M. Adams. 2009. Phenotypic plasticity of leaf shape along a temperature gradient in Acer rubrum. PLoS One 4:e7653.

Sanchez, S. and R. R. Schoch. 2013. Bone histology reveals a high environmental and metabolic plasticity as a successful evolutionary strategy in a long-lived homeostatic Triassic temnospondyl. Evolutionary Biology 40:627-647.

Scheiner, S. M., M. Barfield, and R. D. Holt. 2019. The genetics of phenotypic plasticity. XVII. Response to climate change. Evolutionary Applications 13:388-399.

Scheiner, S. M. and N. A. Levis. 2021. The loss of phenotypic plasticity. In D. W. Pfennig, ed., Phenotypic Plasticity and Evolution: Causes, Consequences, Controversies. CRC Press, Boca Raton, FL.

Schimmelmann, A., C. B. Lange, J. Schieber, P. Francus, A. E. K. Ojala, and B. Zolitschka. 2016. Varves in marine sediments: A review. Earth-Science Reviews 159:215-246.

Schluter, N. 2016. Ecophenotypic variation and developmental instability in the Late Cretaceous echinoid micraster brevis (Irregularia; Spatangoida). PLoS One 11:e0148341.

Schneider, S., F. T. Fürsich, T. Schulz-Mirbach, and W. Werner. 2010. Ecophenotypic plasticity versus evolutionary trends-morphological variability in Upper Jurassic bivalve shells from Portugal. Acta Palaeontologica Polonica 55:701-732.

Schoch, R. R. 2014. Life cycles, plasticity and paleoecology in temnospondyl amphibians. Palaeontology 57:517-529.

Schrøder, A. E., B. W. Lauridsen, and F. Surlyk. 2018. Ecophenotypic asymmetry in the middle Danian brachiopod Obliquorhynchia flustracea caused by adaptation to attachment on the coral Dendrophyllia candelabrum. Lethaia 51:86-95.

Sheldon, P. R. 1987. Parallel gradualistic evolution in Ordovician trilobites. Nature 330:561-563.

Simola, H. 2013. Diatom records: Freshwater laminated sequences, pp. 849-859. In S. A. Elias, and C. J. Mock, eds., Encyclopedia of Quaternary Science (2nd edition) Elsevier, Amsterdam.

Snell-Rood, E. and S. Ehlman. 2021. The ecology and evolution of plasticity. In D. W. Pfennig, ed., Phenotypic Plasticity and Evolution: Causes, Consequences, Controversies. CRC Press, Boca Raton, FL.

Sol, D. 2007. Do successful invaders exist? Pre-adaptations to novel environments in terrestrial vertebrates, pp. 127-141. In W. Nentwig, ed., Biological Invasions. Springer, Berlin.

Standen, E. M., T. Y. Du, and H. C. Larsson. 2014. Developmental plasticity and the origin of tetrapods. Nature 513:54-58.

Starck, J. M. and A. Chinsamy. 2002. Bone microstructure and developmental plasticity in birds and other dinosaurs. J Morphol 254:232-246.

Sultan, S. E. 2021. Plasticity as an intrinsic property of organisms. In D. W. Pfennig, ed., Phenotypic Plasticity and Evolution: Causes, Consequences, Controversies. CRC Press, Boca Raton, FL.

Taylor, P. D. 2005. Bryozoans and palaeoenviornmental interpretation. Journal of the Palaeontological Society of India 50:1-11.

Taylor, P. D. and K. S. Schindler. 2004. A new Eocene species of the hermit-crab symbiont Hippoporidra (Bryozoa) from the Ocala Limestone of Florida. Journal of Paleontology 78:790-794.

Trinkaus, E., S. E. Churchill, and C. B. Ruff. 1994. Postcranial robusticity in Homo. II: Humeral bilateral asymmetry and bone plasticity. American Journal of Physical Anthropology 93:1-34.

Tucić, B., S. Budečević, S. Manitašević Jovanović, A. Vuleta, and C. P. Klingenberg. 2018. Phenotypic plasticity in response to environmental heterogeneity contributes to fluctuating asymmetry in plants: First empirical evidence. Journal of Evolutionary Biology 31:197-210. 
Twitchett, R. J. 2007. The Lilliput effect in the aftermath of the end-Permian extinction event. Palaeogeography, Palaeoclimatology, Palaeoecology 252:132-144.

Uller, T., N. Feiner, R. Radersma, I. S. C. Jackson, and A. Rago. 2019. Developmental plasticity and evolutionary explanations. Evolution \& Development 22:47-55.

Van Bocxlaer, B., D. V. Damme, and C. S. Feibel. 2008. Gradual versus punctuated equilibrium evolution in the Turkana Basin molluscs: Evolutionary events or biological invasions? Evolution 62:511-520.

Van der Valk, T., P. Pečnerová, D. Díez-del-Molino, A. Bergström, J. Oppenheimer, S. Hartmann, G. Xenikoudakis, J.A. Thomas, M. Dehasque, E. Sağlıcan, F.R. Fidan, I. Barnes, S. Liu, M. Somel, P.D. Heintzman, P. Nikolskiy, B. Shapiro, P. Skoglund, M. Hofreiter, A.M. Lister, A. Götherström and L. Dalén. 2021. Million-year-old DNA sheds light on the genomic history of mammoths. Nature, doi.org/10.1038/ s41586-021-03224-9.

Vane-Wright, R. I. 2014. What is life? And what might be said of the role of behavior in its evolution? Biological Journal of the Linnean Society 112:219-241.

Voje, K.L. 2016. Tempo does not correlate with mode in the fossil record. Evolution 70:2678-2689.

Walters, R. J. and M. Hassall. 2006. The temperature-size rule in ectotherms: May a general explanation exist after all? The American Naturalist 167:510-523.

Wang, X.-D., T. Sugiyama, and F. Zhang. 2004. Intraspecific variation in a new solitary rugose coral, Commutia exoleta, from the Lower Carboniferous of the Baoshan Block, Southwest China. Journal of Paleontology 78:77-83.

Webster, M. 2015. Ontogeny and intraspecific variation of the early Cambrian trilobite Olenellus gilberti, with implications for olenelline phylogeny and macroevolutionary trends in phenotypic canalization. Journal of Systematic Palaeontology 13:1-74.

Webster, M. 2019. Morphological homeostasis in the fossil record. Seminars in Cell and Developmental Biology 88:91-104.

Webster, M. and M. L. Zelditch. 2008. Integration and regulation of developmental systems in trilobites, pp. 427-434. In I. Rábano, R. Gozalo, and D. García-Bellido, eds., Advances in Trilobite Research. Instituto Geológico y Minero de España, Madrid.

West-Eberhard, M. J. 2003. Developmental Plasticity and Evolution. Oxford University Press, Oxford.

Williamson, P. G. 1982. Williamson replies. Nature 296:611-612.

Wilmsen, M. and A. Mosavinia. 2011. Phenotypic plasticity and taxonomy of Schloenbachia varians (J. Sowerby, 1817) (Cretaceous Ammonoidea). Paläontologische Zeitschrift 85:169-184.

Wimberger, P. H. 1994. Trophic polymorphisms, plasticity, and speciation in vertebrates, pp. 19-43. In D. J. Stouder, K. L. Fresh, and R. J. Feller, eds., Theory and Application of Fish Feeding Ecology. University of South Caroline Press, Columbia, SC.

Witts, J. D., N. H. Landman, M. J. Hopkins, C. E. Myers, and A. Brayard. 2020. Evolutionary stasis, ecophenotypy and environmental controls on ammonite morphology in the Late Cretaceous (Maastrichtian) Western Interior Seaway, USA. Palaeontology 63:791-806.

Wright, T. F., J. R. Eberhard, E. A. Hobson, M. L. Avery, and M. A. Russello. 2010. Behavioral flexibility and species invasions: The adaptive flexibility hypothesis. Ethology Ecology \& Evolution 22:393-404.

Wund, M. A., J. A. Baker, B. Clancy, J. L. Golub, and S. A. Foster. 2008. A test of the "flexible stem" model of evolution: Ancestral plasticity, genetic accommodation, and morphological divergence in the threespine stickleback radiation. The American Naturalist 172:449-462. 